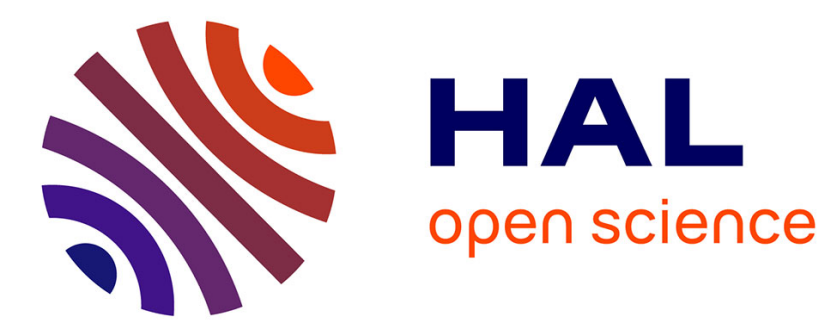

\title{
Developmental dyslexia: The visual attention span deficit hypothesis
}

Marie-Line Bosse, Marie-Josèphe Tainturier, Sylviane Valdois

\section{To cite this version:}

Marie-Line Bosse, Marie-Josèphe Tainturier, Sylviane Valdois. Developmental dyslexia: The visual attention span deficit hypothesis. Cognition, 2007, 104 (2), pp.198-230. 10.1016/j.cognition.2006.05.009 . hal-00817777

\section{HAL Id: hal-00817777 https://hal.science/hal-00817777}

Submitted on 25 May 2013

HAL is a multi-disciplinary open access archive for the deposit and dissemination of scientific research documents, whether they are published or not. The documents may come from teaching and research institutions in France or abroad, or from public or private research centers.
L'archive ouverte pluridisciplinaire HAL, est destinée au dépôt et à la diffusion de documents scientifiques de niveau recherche, publiés ou non, émanant des établissements d'enseignement et de recherche français ou étrangers, des laboratoires publics ou privés. 


\title{
Developmental dyslexia: The Visual attention span deficit hypothesis
}

\author{
Marie-Line Bosse*, Marie Josèphe Tainturier** and Sylviane Valdois*, \\ *Laboratoire de Psychologie et Neuro-Cognition (UMR 5105 CNRS) \\ Université Pierre Mendès France, Grenoble, France \\ ** School of Psychology, University of Wales, Bangor, UK.
}

Article paru dans Cognition 104, (2007), 198-230

\begin{abstract}
The visual attentional (VA) span is defined as the amount of distinct visual elements which can be processed in parallel in a multi-element array. Both recent empirical data and theoretical accounts suggest that a VA span deficit might contribute to developmental dyslexia, independently of a phonological disorder. In this study, this hypothesis was assessed in two large samples of French and British dyslexic children whose performance was compared to that of chronological-age matched control children. Results of the French study show that the VA span capacities account for a substantial amount of unique variance in reading, as do phonological skills. The British study replicates this finding and further reveals that the contribution of the VA span to reading performance remains even after controlling IQ, verbal fluency, vocabulary and single letter identification skills, in addition to phoneme awareness. In both studies, most dyslexic children exhibit a selective phonological or VA span disorder. Overall, these findings support a multi-factorial view of developmental dyslexia. In many cases, developmental reading disorders do not seem to be due to
\end{abstract}


phonological disorders. We propose that a VA span deficit is a likely alternative underlying cognitive deficit in dyslexia.

Key words: developmental dyslexia, phoneme awareness, visual attention span, dyslexic subtypes, reading acquisition, French, children.

\section{Acknowledgements}

This research was supported by a GIS grant (GIS "Ecole et sciences cognitives" n ${ }^{\circ} \mathrm{AL} 24 \mathrm{~b}$ ) and a Joint Activities Award Scheme from the British Academy to Marie Josèphe Tainturier. Marie Line Bosse was supported by a doctoral grant from the "Société de Neuropsychologie de Langue Française" (French Society of Neuropsychology). We wish to thank Serge Carbonnel and the anonymous reviewers for their helpful comments, Rémi Drouillet and Marc Reichelt for assisting in statistical analyses. We also thank the pupils, teachers and academic staff of Gabriel Péri, Saint Martin d'Hères and Jules Ferry Grenoble Elementary schools, of Le Touvet secondary school (France) and of the primary schools who took part in this work in the areas of North Wales, Herefordshire, Cheshire and Greater Manchester (United Kingdom). We also thank the staff of the "Centre Référent pour le diagnostic des troubles du langage et des apprentissages" (Reference Centre for the diagnosis of language and learning disorders) of the CHU of Grenoble as well as Hagar Levy-Sebbag, Vania Herbillon, Rachel Allison Zammit and Heather Roberts, for assistance in collecting data. Part 
of this work was presented at the Bangor Dyslexia Conference (Bangor, Wales, July 2003), at the British Dyslexia Association Meeting (Warwick, England, March 2004) and at the first Congress of the European Neuropsychological Societies (Modena, Italy, April 2004). Correspondence concerning this article should be addressed to Sylviane Valdois (Sylviane.Valdois@upmf-grenoble.fr) or Marie-Line Bosse (Marie-Line.Bosse@upmfgrenoble.fr).

Developmental dyslexia is theoretically defined as resulting from a cognitive dysfunction, itself secondary to a neurobiological dysfunction. Decades of intensive research in cognitive neuropsychology, neuroscience and genetics have resulted in suggestions for possible causes of dyslexia. The proposal of a phonological deficit as the cognitive basis of developmental dyslexia is now widely accepted (Frith, 1997; Snowling, 2001; Vellutino, Fletcher, Snowling, \& Scanlon, 2004; Ziegler \& Goswami, 2005) although this disorder might be secondary to more basic auditory temporal processing deficits (Merzenich et al.,1996; Tallal, 1980; Tallal et al., 1996; Tallal, Miller, \& Fitch, 1993; Tallal, Miller, Jenkins \& Merzenich, 1997, for a review) or speech perception deficits (Breier, Fletcher, Foorman \& Gray, 2002; Mody, Studdert-Kennedy, \& Brady, 1997; Serniclaes, Sprenger-Charolles, Carré, \& Démonet, 2001; Farmer \& Klein, 1995). In addition, low level visual processing disorders induced by a magnocellular dysfunction may contribute to developmental dyslexia (Livingstone, Rosen, Drislane, \& Galaburda, 1991; Lovegrove, Martin, \& Slaghuis, 1986; Stein, 1991, 2001, 2003; Stein \& Fowler, 1993; Stein, Talcott, \& Witton, 2001; Stein \& Walsh, 1997, Vidyasagar, 
2004). Perceptual attentional disorders have also been reported (Buchholz \& Davies, 2005;

Facoetti \& Molteni, 2001; Hari \& Renvall, 2001, Pammer, Lavis, Hansen \& Cornelissen, 2004; and Facoetti, 2004, for a review). However, perceptual attentional and low level visual processing deficits tend to co-occur with phonological disorders, suggesting that the latter may be the proximal source of the reading acquisition difficulties (Cestnick, 2001; Facoetti et al., 2003; Facoetti, Lorusso, Cattaneo, Galli \& Molteni, 2005; Ramus et al., 2003; Slaghuis, Lovegrove, \& Davidson, 1993; Van Ingelghem, Van Wieringen, Wouters, Vandenbussche, \& Onghena, 2001). Similarly, the cerebellar theory of dyslexia (Fawcett \& Nicolson, 1999; Fawcett \& Nicolson, 2001; Fawcett, Nicolson, \& Dean, 1996; Nicolson, Fawcett, \& Dean, 2001) proposes that problems in motor control affecting speech articulation and automation might result in poor phonological skills, and that it is the phonological deficit which is directly responsible for reading acquisition disorders. Thus, the general tendency is to treat developmental dyslexia as a unitary syndrome, with a single underlying cause: a phonological deficit.

In spite of the success of the phonological hypothesis, reports of opposite patterns of performance in developmental dyslexia (i.e., phonological vs. surface variants) and of good phoneme awareness skills in some dyslexic children (Broom \& Doctor, 1995; Castles \& Coltheart, 1996; Brunsdon, Coltheart \& Nickels, 2005; Goulandris \& Snowling, 1991; Hanley \& Gard, 1995; Hanley, Hastie, \& Kay, 1992; Job, Sartori, Masterson, \& Coltheart, 1984; McCloskey \& Rapp, 2000; Romani \& Stringer, 1994; Romani, Ward, \& Olson, 1999; Temple, 1984; Valdois et al., 2003) challenge the view that a selective phonological core deficit is the source of reading disorders in all cases of developmental dyslexia. The heterogeneity of the manifestations of dyslexia has lead several researchers to entertain the alternative view that developmental dyslexia may actually arise as a result of multiple and 
independent cognitive disorders (Wolf \& Bowers, 1999; Di Betta \& Romani, 2005; Romani, Di Betta, Tsouknida \& Olson, submitted). For example, the double deficit hypothesis (Wolf \& Bowers, 1999; Wolf et al., 2002; Savage \& Frederickson, 2005) postulates that phonological deficits and processes underlying rapid automated naming represent two distinct sources of reading dysfunction. Although there is a growing body of evidence showing naming speed deficits in developmental dyslexia (Ho, Chan, Tsang, \& Lee, 2002; Wimmer, Mayringer, \& Landerl, 2000; Wolf \& Bowers, 1999; Wolf et al., 2002), the nature of the cognitive processes underlying rapid automated naming and their relationship with reading acquisition remain poorly understood. Moreover, most dyslexic children appear to exhibit both phonological and rapid automated naming difficulties, which weakens the claim that these two disorders are independent (Wolf et al., 2002).

In line with a multifactorial view of dyslexia, difficulties in processing multi-element strings have recently been documented (Bednarek et al., 2004; Hawelka \& Wimmer, 2005; Pammer et al., 2004; Valdois et al., 2003). These difficulties might reflect deficits in the allocation of attention across letter or symbol strings, limiting the number of elements that can be processed in parallel during reading. The purpose of the experiments presented in this paper was to provide evidence in support of the existence of a visuo-attentional span disorder in dyslexic children.

The VA span deficit hypothesis is theoretically grounded in the connectionist multitrace memory model of polysyllabic word reading proposed by Ans, Carbonnel and Valdois (1998; hereafter ACV98). Although models of eye movement control in reading (Reichle, Rayner, \& Pollatsek, 2003) and some models of word recognition (Behrmann, Moscovitch, \& Mozer, 1991; Laberge \& Samuels, 1974; Laberge \& Brown, 1989) emphasise the role of visual attention, most reading theories do not specify the attentional processes involved in the 
visual analysis of letter strings, assuming that they are peripheral mechanisms that are not an integral part of the reading process ( Coltheart, Curtis, Atkins, \& Haller, 1993; Coltheart, Rastle, Perry, Langdon, \& Ziegler, 2001; Harm \& Seidenberg, 1999; Plaut, McClelland, Seidenberg, \& Patterson, 1996; Seidenberg \& McClelland, 1989). On the contrary, the connectionist multi-trace model of polysyllabic word reading (Ans et al., 1998) integrates visual attentional processes as part of the reading system and specifies how these processes can lead to specific reading disorders when damaged.

The model, outlined in Figure 1, postulates that reading relies on two types of reading procedures, global versus analytic, that differ in the kind of VA and phonological processing they involve. Insert Figure 1

First, the two reading procedures differ in the size of the VA window through which information from the orthographic input is extracted. In global reading mode, the VA window extends over the whole sequence of the input letter-string whereas the VA window narrows down to focus attention successively on different parts of the input when reading in analytic mode. According to the model, global processing typically requires a larger VA span than analytic processing, although analytic processing itself usually requires a VA span larger than a single letter. Second, the two reading procedures also differ with respect to phonological processing. In global mode, the entire phonological output is generated in a single step. In analytic mode, phonological outputs corresponding to each focal sequence (i.e., letters within the VA window) are successively generated and have to be maintained in short-term memory in order to remain available at the end of processing. Although the two procedures are not $\underline{\mathrm{a}}$ priori dedicated to the processing of a particular type of letter string (real word vs. pseudo- 
word), most familiar words are processed as a whole by the network, whereas global processing typically fails for pseudo-words which are then processed analytically.

The network was tested for its ability to account for skilled reading (Valdois et al., in press) and acquired dyslexia following specific damage. Ans et al. (1998) demonstrated that a moderate reduction of the VAW size prevents reading in global mode. This reduction simulated a surface dyslexia profile, with a selective disruption of irregular word reading giving rise to regularisation errors. Performance was more severely impaired following a more severe reduction of the VAW. Irregular words continued to be the most affected class of items, but the number of errors increased on both regular words and pseudo-words. In contrast, acquired phonological dyslexia was interpreted as resulting from an independent disorder affecting phonological processing.

By analogy to acquired disorders, the model suggests that a selective visual attentional or phonological deficit might impact on reading acquisition and result in patterns of developmental surface or phonological dyslexia. In support of this prediction, Valdois et al. (2003) reported two contrasted cases of developmental dyslexia showing that phonological and VA span disorders could dissociate in dyslexic children. In this study, the VA span was estimated using two tasks which required the report of a single letter or of all of the letters of briefly presented multi-letter strings. These two tasks of partial and global report were inspired from those initially created by Averbach and collaborators (Averbach \& Coriell, 1961; Averbach \& Sperling, 1968) to study the processing of letter information perceived during a single fixation. Since then, the whole and partial report procedures have been used in a wide range of visual attention studies and with several variants to assess both normal (Dixon, Gordon, Leung; \& Di Lollo, 1997; Giesbrecht \& Dixon, 1999; Hagenaar \& Van der Heijden, 1995; Mewhort, Campbell, Marchetti, \& Campbell, 1981) and impaired (Arguin \& 
Bub, 1993; Duncan, Bundesen, Olson, Humphreys, \& Chavda, 1999; Duncan et al., 2003; Habekost \& Bundesen, 2003; Rapp \& Caramazza, 1991) visual attention processing. In the present study, the partial and global report tasks were used to estimate the participants' VA span.

Our purpose in the present paper is to provide evidence for the independence between the phonological processing deficit and the VA span disorder in developmental dyslexia. Second, we will demonstrate that the VA span deficit accounts for unique variance in the reading performance of dyslexic participants beyond that explained by phonological skills. For this purpose, findings from two studies conducted on two large samples of French and British dyslexic children are reported. In both studies, children were given a comprehensive neuropsychological battery including assessment of reading, phoneme awareness and VA span. The French study (Experiment 1) examines how dyslexic children's phonological processing skills and VA span relate to reading performance after control for age effects. The

British study (Experiment 2) is a replication of the French study controlling for additional factors (IQ, verbal fluency, vocabulary, letter identification skills) which are likely to contribute to reading performance.

\section{Experiment 1}

\section{$\underline{\text { Participants }}$}

One hundred and twenty three French native speakers took part in this experiment: 68 dyslexic participants and 55 control children. The dyslexic group consisted of 68 children (44 males) with a mean chronological age of 11 years 6 months ( $\mathrm{SD}=20$ months; range: 8;9 - 
16;2). They had normal IQ ${ }^{1}$, attended school regularly and none of them had any history of neurological illness or brain damage. They were recruited from education authorities and dyslexia centres and most of them had received some degree of remedial instruction in reading, spelling or oral language. All were extremely delayed readers: they achieved a reading age of 7 years and 11 months on average on the "Alouette Reading Test" (Lefavrais, 1965), corresponding to a mean reading delay of 42 months $(S D=16$ months; range $=20$ months to 87 months).

Performance of the dyslexic participants was compared to that of 55 normally developing control children (33 males) matched on chronological age (CA). Their chronological age (mean age $=11$ years 6 months, $S D=14$ months, range: 9;7 $-13 ; 2$ ) was equivalent to that of the dyslexic group $(\mathrm{t}(121)=0.24, \mathrm{p}=.80)$ but their reading age (mean reading age $=11$ years 5 months, $\mathrm{SD}=15$ months, range: $8 ; 11-14 ; 3$ ) was significantly higher $(\mathrm{t}(121)=15.84, \mathrm{p}<.0001)$

\section{$\underline{\text { Material and Measures }}$}

The test session included three reading tasks, three metaphonological tasks and two visual attentional processing tasks.

\section{The Reading Tasks}

Regular and exception word reading

Children had to read two lists of 20 exception words of high (HF, e.g., "sept" seven) or low frequency (LF; e.g., "paon" peacock), and two lists of $20 \mathrm{HF}$ (e.g., "nuit" night) and LF (e.g., "bise" north wind) regular words (see Appendix 1). The four word lists (ODEDYS Test, Jacquier-Roux, Valdois \& Zorman, 2002) were matched for letter and syllable length, and

\footnotetext{
${ }^{1}$ Each participant had been given an intellectual efficiency assessment (using the WISC-R or the Raven matrices) showing a normal or above normal IQ. However, we cannot provide the specific scores because most
} 
grammatical class; irregular and regular words were also matched for frequency according to the norms provided by Lété, Sprenger-Charolles, and Colé (2004). Each list was printed in column on a single sheet, in lower-case letters (Times font, 14-point). Children were asked to read aloud each word successively as they moved through the list from top to bottom. They were instructed to read each list as quickly and accurately as possible, although only the error data were recorded.

\section{Pseudoword reading}

Most dyslexic children $(\mathrm{N}=50)$ were given a list of 90 legal pseudo-words (see Appendix 1) that varied in length from 4 to 8 letters long and 1 to 3 syllables (e.g., "scolp" /skOlp/, "munate" /mynat/, "ascodeau" /askodo/). The pseudo-words were constructed from a list of 90 consistent words by substituting some of their constituent letters but preserving the phonological class of the corresponding phonemes (for example, the previous pseudo-words were generated from the words "scalp" /scalp/ scalp, "minute" /minyt/ minute and "escabeau" /Eskabo/ stool respectively). The 90 pseudo-words were presented under the same conditions as the words.

For practical reasons, all the control participants and 18 dyslexic children were administered a reduced list of 40 pseudo-words with the same characteristics as the extended list. Children were told that the items to read were invented words. They were asked to read them aloud as quickly and accurately as possible. The scores of the participants exposed to the extended list (PW: pseudo-word reading score) were transformed as a ratio calculated on 40, in order to allow comparison with the RW and EW scores 


\section{Tests of Phonological Awareness}

\section{Phonemic segmentation task}

Twenty words were presented auditorily to the participants who had to successively sound out each of the word's constituent phonemes. For example, the word /kado/ ("cadeau" present) was pronounced by the experimenter and the child was required to say $/ \mathrm{k} /-/ \mathrm{a} /-/ \mathrm{d} /$ - /o/. The words were 4.2 phonemes long on average (range 3-6), 12 words ended with a closed syllable (CVC; e.g., /fuR/ "four" oven; /kuloeR/ "couleur" color), while the remaining 8 words only included CV syllables (e.g., /kado/ "cadeau" present; /pâtalô/ "pantalon" trousers).

\section{Phoneme deletion task}

The participants were asked to delete the first sound of a spoken word and to produce the resulting pseudo-word (e.g., "outil" /uti/ $\rightarrow$ /ti/; "placard" /plakaR/ $\rightarrow$ /lakaR/). Twenty experimental words were presented: 7 began with a vocalic phoneme corresponding to a multiple letter grapheme so that the omission of the first letter (instead of the first phoneme) yielded incorrect responses; 9 began with a consonantal cluster, 4 with a singleton.

\section{Acronym task}

Three words were successively pronounced by the experimenter (one word per second). The children were required to extract the first phonemes of each word and combine them to produce a new word. For example, the subject heard /kan/-/ubli/-/dãs/ ("cane" duck, "oubli" forgetting "danse" dance) and had to say /kud/ "coude" elbow. The test comprised 15 series of 3 words made up of 3 phonemes on average (range 2-5). Six words began with a vocalic phoneme corresponding to a digraph so that an erroneous word was generated if the first letter was extracted instead of the first phoneme (the response would be /kOd/ "code" 
code if orthographically biased in the previous example). Five words began with a VC syllable so that the rime had to be segmented in order to extract the initial phoneme.

\section{Visual Attentional span tasks}

Bar probe task: whole report condition

On each trial, the participants were required to orally report a string of 5 letters briefly presented at the centre of the monitor screen.

Stimuli: Twenty random 5-letter strings (e.g., R H S D M) were built up from 10

consonants (B, P, T, F, L, M, D, S, R, H). Each letter was used 10 times and appeared twice in each of the five positions. The letters were presented in upper-case (Geneva 24) in black on a white background. The strings contained no repeated letters. The distance between letters was $1 \mathrm{~cm}$ to minimise lateral masking. The array subtended an angle of approximately $3.8^{\circ}$.

Procedure: At the start of each trial, a central fixation point was presented for $1000 \mathrm{~ms}$ followed by a blank screen for $500 \mathrm{~ms}$. A letter string was then presented at the centre of the display for $200 \mathrm{~ms}$. The participants' task was to report verbally all the letters immediately after they disappeared. After having written their response, the experimenter pressed a button to start the next trial. The experimental task was preceded by five training trials for which participants received feedback. No feedback was given during the 20 test trials. Two scores were recorded: the first score STR corresponds to the number of 5- letter strings accurately reported (STR; $\max =20)$; the second corresponds to the number of letters accurately reported across the 20 trials (LET score; $\max =100$ ). 
The participants were required to orally report a single cued letter among the 5 letters of each briefly presented string.

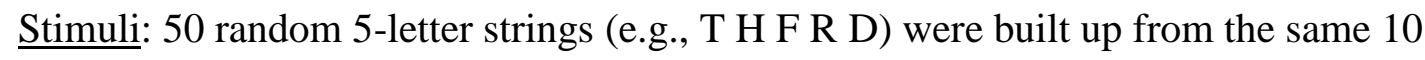
consonants used in the whole report condition (with no repeated letter). The occurrence of each letter was 25 and each appeared five times in each position. As previously, letters were presented in upper-case (Geneva 24) in black on a white background, spaced by one centimetre. The probe indicating the letter to be reported was a vertical bar presented for 50 $\mathrm{ms}, 1 \mathrm{~cm}$ below the target letter. Each letter was used as target once in each position. Procedure: At the start of each trial, a central fixation point was presented for $1000 \mathrm{~ms}$ followed by a blank screen for $500 \mathrm{~ms}$. A 5-letter string was then presented at the centre of the display monitor for $200 \mathrm{~ms}$. At the offset of the letter string, the bar probe appeared for $50 \mathrm{~ms}$. Participants were asked to report the cued letter only. They were instructed to be as accurate as possible and no time pressure was applied. After their oral response, the experimenter pressed a button to start the next trial. The experimental trials were preceded by 10 training trials for which participants received feedback. No feedback was given during the 50 test trials. The score was the number of letters accurately reported (PAR, $\max =50)$.

\section{General Procedure}

The dyslexic children were tested individually in two 1-hour sessions, 8 days apart on average. The control children were tested individually in one or two sessions in a quiet room of their school. The phonological, visual attentional and reading tests were presented in a random order that varied from one child to the other.

\section{$\underline{\text { Design and Analyses }}$}


A correlation analysis was first conducted on the measures of age, reading (RW, EW and PW), phonological awareness (SEG, DEL and ACR, Cronbach's alpha $=.71)$ and visual attentional skills (STR, LET and PAR, Cronbach's alpha $=.81)$, for the dyslexic children and controls. Second, to reduce the data set before exploring the concurrent predictors of reading skills among dyslexic and normally developing children, we conducted a principal components analysis with varimax rotation on the data from the 3 phonological tasks, the 3 visual scores and age. All factor loadings greater than $+/-0.70$ were used for interpretation. Finally, the factor scores derived on the basis of the principal components analysis were used to explore the concurrent predictors of reading sub skills.

\section{$\underline{\text { Results }}$}

\section{Overview of the Participants' Performance}

Performance of the dyslexic and control participants on each task of the assessment battery is shown in Table 1.

Insert Table 1 about here

As a group, the dyslexic children performed more poorly than controls on the three reading tasks, on two of the phonological tasks and on the three VA measures (see t tests in Table 1). Dyslexic performance was further characterised by a higher variability on all the reading scores, all the phonological scores and two VA measures (see Table 1).

\section{Correlation Analyses}


A correlation analysis was conducted on measures of age, reading skills, phonological awareness and visual attentional span for all the subjects.

Insert Table 2 about here

As would be expected, strong correlations were found between the three measures of reading (RW, EW and PW), between the three measures of phonological awareness (SEG, DEL and ACR) and between the three measures of visual attention span (STR, LET and PAR). In addition, all reading scores correlated with both the phonological (from .20 to .46) and VA measures (from .49 to .69), and some phonological measures correlated slightly but significantly with some VA measures (from .18 to .31). However, there were significant correlations of chronological age with all the reading measures and VA processing skills. A correlation analysis controlling for chronological age (cf. Table 3) was thus conducted for the dyslexic participants $(\mathrm{N}=68)$.

Insert Table 3 about here

The analysis revealed strong correlations between the measures thought to reflect the same cognitive processes - phonological awareness (SEG, DEL and ACR), visual attentional processing (STR, LET and PAR) - after controlling for chronological age. As expected, PW reading correlated with the three phoneme awareness tasks but word reading (RW and EW) only correlated with performance in the segmentation task. More interestingly, there were strong correlations of VA processing skills with reading sub skills but none of the correlations between phonological and VA span skills was significant, as would be expected under the hypothesis that VA span and phonological skills are independent abilities. 
To reduce the data set before exploring the concurrent predictors of reading skills among the dyslexic and control children, we conducted a principal components analysis with varimax rotation on the data from the three phonological tasks, the three VA tasks and age.

Insert Table 4 about here

This analysis revealed a three-factor solution. The first factor (called VA factor hereafter) accounted for $35.8 \%$ of the variance (eigenvalue $=2.5$ ) and received high loadings from global and partial report. The second factor - called Phonological Factor; $27.1 \%$ of variance, eigenvalue $=1.9-$ received high loadings from phoneme segmentation, onset deletion and acronyms. The third factor was Age (16.4\% of variance, eigenvalue=1.1). The three factors accounted cumulatively for $79.3 \%$ of the variance. The rotated factor loadings are displayed in Table 4.

\section{Predictors of Reading Skills}

Individual factorial coefficients, derived from the factorial weights of the principal components analysis, were used to explore the concurrent predictors of reading skills in the dyslexic population. Two different sets of hierarchical regressions were carried out: one forcing the entry of the phonological factor as the second step and the other forcing the entry of the VA factor in step 2. In all cases, chronological age factor was entered as step 1. The two factors of interest (i.e.,, VA and phonological factors) were entered alternately at step 3 of the analyses to assess their unique contribution to general reading level, regular word, exception word and pseudo-word reading. Results of these analyses are shown in Table 5. 
Insert Table 5 about here

Age accounted for a significant $13.2 \%$ of the variance in the prediction of exception word reading but did not contribute to pseudo-word reading. Both the phonological and VA factor scores were significant and independent predictors of reading performance, after age was controlled. More specifically, phonological skills accounted for $7.5 \%$ and $20.3 \%$ of unique variance in exception word and pseudo-word reading respectively ${ }^{2}$. Moreover and as expected, VA span abilities were significant independent predictors of reading performance, accounting for $29.4 \%$ and $36.4 \%$ of unique variance in exception word and pseudo-word reading respectively.

Thus, the analysis revealed that, whatever the influence of age and phoneme awareness skills, the VA factor was a significant additional predictor of reading accuracy performance in the dyslexic group. The phonological factor also significantly contributed to reading accuracy performance after control for age and visual attentional skills. These data confirm the well-documented link between pseudo-word reading and phonological awareness. They further emphasise the existence of a strong relationship between reading performance and VA processing skills in dyslexic children.

\section{Dyslexic Subgroups}

\footnotetext{
${ }^{2}$ As shown in Table 5, the phonological factor yielded a more significant R2 change when it was entered at step 3 ( $\mathrm{R} 2$ change $=.203$ for PWs for example) than when it was entered at step 2 (R2 change=.139). This is somewhat unusual as regressors typically account for a smaller part of variance when entered latter in the analysis. This is because regressors are usually either unrelated or positively correlated. In the present case, the regressors are the phonological and VA factorial coefficients obtained from the Principal components analysis done on the overall population (including performance of both the dyslexic and control participants). The two factorial coefficients were orthogonal and uncorrelated on the overall population; however these coefficients are in fact slightly and negatively correlated $(\mathrm{r}=-.13)$ in the analysis restricted to the dyslexic population. In this unusual case, extracting the part of variance explained by one factor in fact makes the profile of performance in reading closer to that explained by the second factor. Accordingly, more significant R2 changes are found for both the phonological and VA factor when entered at step 3 than when entered at step 2.
} 
The previous analyses showed that the phonological and visual attentional processing skills contributed independently to reading performance in the dyslexic group. One main goal of this study was to determine whether a proportion of dyslexic children could be characterised as suffering from a selective visual span deficit. Of course, we also expected that a significant proportion of children would show a selective phonological processing deficit. In order to test these hypotheses directly, we examined the distribution of the individual visual and phonological factorial coefficients provided by the principal components analysis. Children whose score fell below the $10^{\text {th }}$ percentile of the CA group factorial coefficients (- 0.36 and - 0.46 respectively for VA and phonological coefficients) were considered as being impaired on that factor. Figure 2 displays the distribution of VA and phonological coefficients in dyslexic and control participants. It reveals that the dyslexic participants fell into four subgroups. First, as well documented in the literature, some dyslexic children (19\%) showed a selective phonological deficit (see lower right quadrant). However, the most critical finding is that a high proportion (44\%) of children exhibited a VA span deficit without an associated phonological deficit (see upper left quadrant). In addition, 15\% of children showed both disorders (lower left quadrant) while $22 \%$ did not seem to be impaired in either VA span or phonology (see below for possible explanations).

Insert Figure 2 about here

\section{$\underline{\text { Discussion }}$}

The main findings of Experiment 1 are as follows: First, we were able to demonstrate that reading performance is highly correlated not only with phonological skills but also with 
the measures of visual attentional span. Second, the analyses restricted to the dyslexic population showed that both phonological and visual attentional scores correlate with pseudoword and exception word reading but that they do not correlate with each other. Third, multiple regression analyses revealed that the phonological awareness and VA span measures each made a unique contribution to the reading performance of dyslexic children. Phoneme awareness accounted for a substantial amount of variance in pseudo-word reading, confirming the strong impact of phonological processing on analytic reading skills. However, and in accordance with previous reports (Griffiths \& Snowling, 2002), phonological skills only slightly contributed to exception word reading. By contrast, VA processing skills explained a large and similar amount of unique variance in both exception word and pseudo-word reading. Finally, Experiment 1 showed that different French dyslexic children appeared to suffer from different associated cognitive deficits, as revealed by the examination of the distribution of factor scores provided by the PCA. While some showed a selective phonological deficit, as well demonstrated in earlier studies, the novel finding is that a large proportion of children showed a selective VA span deficit, which is precisely what we intended to demonstrate. This suggests (but does not directly demonstrate) that different underlying cognitive deficits may lead to dyslexia.

Experiment 2 has two main goals. The first is to replicate and generalise the findings obtained in Experiment 1 on a sample of younger, English-speaking dyslexic children. In experiment 1 , the role of phonology seemed to be smaller than obtained in other studies, which may partly be due to the characteristics of the French language. Indeed, metaphonological development differs across languages (Caravolas \& Bruck, 1993; Cheung, Chen, Lai, Wong \& Hills, 2001, Durgunoglu \& Oney, 1999); phonological awareness 
develops more rapidly in French than in English-speaking children (Duncan, Colé, Seymour, \& Magnan, submitted). In addition, pseudo-word reading is better in learners of more regular orthographies than English (Frith, Wimmer \& Landerl, 1998; Goswami, Ziegler, Dalton \& Schneider, 2003; Seymour, Aro \& Erskine, 2003). In more regular languages, nonword reading difficulties are manifest in slower reading times rather than in lower accuracy (Wimmer, 1993; Landerl, Wimmer \& Frith, 1997, for German; Sprenger-Charolles, Colé, Lacert, \& Serniclaes, 2000; Valdois et al., 2003, for French). In sum, our goal is to demonstrate that, although the influence of phonology may be weaker in French, the fact that some children display a visual attentional span deficit without an associated phonological deficit is not restricted to the French language.

The second aim of Experiment 2 is to rule out the possibility that the findings of Experiment 1 may be due to the influence of uncontrolled factors that could influence reading acquisition. More specifically, and in addition to the factors already controlled in Experiment 1, we will now control directly nonverbal IQ, spoken vocabulary and single letter identification skills (which could directly impact on our VA span measures).

\section{EXPERIMENT 2}

\section{Participants}

Twenty-nine British dyslexic children (mean chronological age $=10$ years 5 months) and 23 chronological age controls (mean age $=10$ years 6 months) participated in Experiment 2. All participants were native English speakers, aged from 9 to 11 years, and had a non verbal standard IQ score of 85 or more (Raven, 1958). None of the children suffered from any learning, behavioural or sensory disorder. On the WRAT test (Wilkinson, 1993), the dyslexic children achieved a reading standard score of 81 and a spelling standard score of 82 on 
average, both corresponding to the $13^{\text {th }}$ percentile. Most children of the control group were recruited in the same classes as the dyslexic children. To be included as controls, children had to score above the 40th percentile on the WRAT reading test. Details of the characteristics of each group are presented in Table 6.

Insert Table 6 about here

The dyslexic group and the control group did not differ significantly in age but did differ in the WRAT reading and spelling tests. They also differed slightly on non verbal IQ.

\section{Material and measures}

\section{Reading tasks}

Participants had to read 20 regular and 20 exception words matched on frequency (Carroll, Davis, \& Richman, 1971) as well as 20 pseudo-words (see Appendix). The three lists were matched in number of syllables and letters; regular words and pseudo-words were also matched in number of phonemes. Each list was presented on a white sheet of A4 paper in lower case format (Verdana, $24 \mathrm{pt}$ ). The time taken to complete each list was recorded together with the accuracy score.

\section{Phonological tests}

Three phonological tasks from the Phonological Assessment Battery (Frederickson, Frith \& Reason, 1997) were used: spoonerisms, rhyme fluency and alliteration fluency. Spoonerism task: In part 1, the child had to replace the onset phoneme of a given word with an alternative onset (e.g., mother with /br/ gives brother). In part 2, the child was asked to exchange the syllable onsets of two given words (e.g., black-crow gives crack-blow). 
Alliteration fluency task: The child was asked to provide as many words as possible that start with a given phoneme $(/ \mathrm{b} /$ and $/ \mathrm{m} /)$, within 30 seconds.

Rhyme fluency task: The child was given a word and asked to recall as many words as possible which rhyme with this word.

\section{Visual Attentional tasks}

The global and partial report tasks described in Experiment 1.

\section{Control tasks}

In addition to non verbal IQ (Raven, 1958), three tasks were used to control a number of cognitive skills which were not the focus of the present research but could affect performance on the tasks of interest.

British Picture Vocabulary test (Dunn, Dunn, Whetton \& Burley, 1997): this test was used to assess the participants' receptive vocabulary knowledge. Participants were given a series of spoken words of increasing difficulty; on each trial, they had to match the word to one of a set of four pictures.

Semantic fluency test (Frederickson et al., 1997). This test requires reporting as many items as possible that belong to a given semantic category (things to eat and animals).

Letter identification skills: The 10 consonants used in the letter report tasks were randomly presented (5 times each) in the centre of the screen at different presentation durations (33 ms, $50 \mathrm{~ms}, 67 \mathrm{~ms}, 84 \mathrm{~ms}$ and $101 \mathrm{~ms})$. The letters had the same physical characteristics as in the visual attentional tasks. Each trial began with a central fixation point which was presented for $1000 \mathrm{~ms}$, followed by a letter. At the offset of the letter, a mask (13 $\mathrm{mm}$ high, $37 \mathrm{~mm}$ wide) was displayed for $150 \mathrm{~ms}$. The participants were asked to name each letter immediately after 
its presentation. The test trials were preceded by 10 practice trials ( 2 for each presentation time) using other letters and for which participants received feedback. The score was the weighted sum of letters accurately identified at each presentation time.

\section{General Procedure}

The tasks were administered in a quiet room at school. The Raven's standard matrices, spelling tests and vocabulary test were administered in small groups. All other tasks were carried out in an individual session. The reading, phonological and visual attentional tasks were alternated with each other during the individual session.

\section{$\underline{\text { Results }}$}

\section{Overview of the participants' performance}

Performance of the dyslexic and control participants on each task of the assessment battery is shown in Table 7.

Insert Table 7 about here

The control participants performed significantly better than the dyslexic participants on all of the tasks, except alliteration fluency. With respect to the control tasks, the two groups differed slightly on vocabulary knowledge $(\mathrm{t}(50)=1.99, \mathrm{p}=.052)$ but did not differ in semantic fluency and in their ability to identify briefly presented single letters.

\section{Correlation analyses}

A correlation analysis was conducted on measures of age, reading skills, phonological awareness, visual attentional skills and control tasks for the whole subjects (cf. Table 8). 
Insert Table 8 about here

Overall, the three reading tasks were strongly correlated for both speed and accuracy (RW, EW and PW), as were the three measures of phonological awareness (SPO, ALL and RHY; Cronbach's alpha=.74) and the three measures of visual attention span (STR, LET and PAR; Cronbach's alpha=.76). All phonological scores correlated with all of reading scores (from 28 to .61) but they were more strongly related to reading accuracy than to reading speed. Strong correlations were also found between all reading scores and all visual attentional scores (from .36 to .71). However, the phonological and visual attentional scores were not correlated, except for the spoonerism and global report tasks. With respect to the control tasks, non verbal IQ correlated with several reading scores and with performance on the VA tasks. Vocabulary knowledge was related to reading accuracy and phonological performance but not to VA scores. Semantic fluency was related to phonological scores. The ability to identify briefly presented isolated letters correlated with reading performance and VA scores but not with phonological performance. Age correlated with word reading accuracy but with none of the phonological or visual attentional scores so that a correlation analysis controlling for age (as done in Experiment 1) was not done in the present experiment.

As in Experiment 1, we conducted a principal components analysis with varimax rotation on the data from the three phonological tasks and the three VA measures.

Insert Table 9 about here

This analysis revealed a two-factor solution (see Table 9) which accounted cumulatively for $74.5 \%$ of the variance. The first factor (Visual processing skills) accounted 
for $40.6 \%$ of the variance (eigenvalue $=2.4$ ) and received high loadings from the global and partial report tasks. The second factor (Phonological skills) accounted for 33.9\% of the variance (eigenvalue $=2.03$ ) and received high loadings from spoonerisms, alliteration fluency and rhyme fluency. Thus, as in Exeriment 1, the different phonological tests and the different VA span tests appear to cluster, but performance on phonological tests is independent from performance on the VA span measures.

\section{Predictors of Reading Skills}

Factor scores derived from the principal components analysis were used in regression analyses to explore the concurrent predictors of reading skills in the dyslexic population $(\mathrm{N}=$ 26, because of three missing data on a control variable). Five control variables (age, IQ, vocabulary, semantic fluency and letter identification) were entered at the earlier steps of two regression analyses in which the phonological and VA factors were respectively entered at step 6. Thus, each analysis evaluated the specific contribution of the visual or phonological factor to regular word, exception word and pseudo-word reading when it was entered 7 th. The results of these analyses are shown in Table 10.

Insert Table 10 about here

The control variables accounted for a significant part of the variance in predicting regular and exception word reading but did not contribute significantly to pseudo-word reading performance ${ }^{3}$. As typically observed, phonological skills accounted for a significant

\footnotetext{
${ }^{3}$ Vocabulary knowledge and letter identification skills did not contribute significantly to reading performance. Age was significantly related to reading accuracy whatever the item to be read. IQ and semantic fluency were not related to pseudo-word reading performance but significantly contributed to RW reading speed for the former and to word reading accuracy for the latter.
} 
amount of variance in reading accuracy for all types of items and also contributed to EW and PW reading speed. Importantly, visual attentional span abilities accounted for a substantial amount of unique variance in reading performance (accuracy and speed) whatever the nature of the items to be read, except for pseudo-word reading accuracy ${ }^{4}$. Thus Experiment 2 replicates one of the main findings of Experiment 1: Both phonological and VA processing skills were independent and significant predictors of reading performance ${ }^{5}$. Importantly, the VA factor remained an independent predictor of reading performance in the dyslexic group, even after controlling for the influence of age, IQ, vocabulary, semantic fluency and letter identification skills.

\section{Dyslexic Subgroups}

The distribution of children's phonological and VA span factor scores (see Figure 3) was examined following the same methodology as in Experiment 1. In experiment 2, the limit values of each factorial coefficient, corresponding to the $10^{\text {th }}$ percentile of control participants' scores, were -.52 and -.75 respectively for visual and phonological coefficients.

Insert Figure 3 about here

\footnotetext{
${ }^{4}$ As previously (Table 5, note 3 ), the two factorial coefficients were found to be negatively correlated (r=-.11) so that the R2 change was more significant when each factor was entered last.

${ }^{5}$ The first factor extracted by the principal components analysis was considered as a visual attentional factor because of high loadings from the global and partial report tasks. However, this factor also captured some information from the spoonerism task. Thus, Factor 1 might be considered as combining both phonological and visual attentional information, although the spoonerisms task may well have a visual mental imagery component. A new principal components analysis was conducted without spoonerism so that Factor 1 only reflected visual attentional performance. This new factor was then used in the regression analysis to specifically investigate the unique contribution of VA processing skills to reading performance. Results were mostly the same, except that the phonological factor no longer accounted for variance in pseudo-word reading accuracy. The significant and independent contribution of VA skills to reading performance remained.
} 
The results on this sample of English-speaking children essentially replicate the results obtained with French-speaking children. As in Experiment 1, most dyslexic participant exhibited either a selective phonological deficit (34.5\%) or a selective VA span deficit (34.5). Only $7 \%$ showed both disorders while $24 \%$ of the participants exhibited none of them. Thus, as in Experiment 1, a substantial proportion of our dyslexic sample showed a visual attentional span deficit in the absence of phonological difficulties.

To control the impact of letter identification on the dyslexic subgroups analysis, we re-ran this analysis on the basis of the residuals of the VA span factor after regressing out letter identification scores. Results showed that $26.9 \%$ of the dyslexic participants persisted in exhibiting a VA span deficit, alone $(23.1 \%)$ or in association with a phonological deficit $(3.8 \%)$.

\section{GENERAL DISCUSSION}

The central issue addressed by this study concerns the nature of the cognitive deficits associated to and potentially responsible for developmental dyslexia. It has become widely accepted that, in cognitive terms, dyslexia is the consequence of a phonological deficit (Ramus et al., 2003; Snowling, 2000; see Vellutino et al., 2004, for a review). However, the heterogeneity of the dyslexic population and the report of cases of dyslexic children without phonological disorders raise the interesting possibility that some patterns of developmental dyslexia might actually reflect non phonological cognitive impairments. Within the framework of the theoretical multitrace memory model (Ans et al., 1998) and in line with recent case-studies (Valdois et al., 2003, Juphard, Carbonnel \& Valdois, 2004), our aim was to demonstrate that a VA span disorder might be associated to developmental dyslexia independently of phonological problems. 
In two experiments, the phonological skills and VA span of French and British dyslexic children were assessed together with their reading performance. The results of both the French and British study showed that phonological and VA scores were unrelated measures suggesting that they tap independent cognitive mechanisms. In addition, phonological awareness significantly contributed to reading accuracy in both languages, independently of the children's VA span. Experiment 2 extended these findings in showing that phoneme awareness further accounted for independent variance in reading speed. Unsurprisingly, our data thus confirm the impact of phonological processing on reading acquisition.

More interestingly, this study uncovered the novel finding that the VA span, as indexed by the global and partial report tasks, contributes to impaired reading performance independently of phonological skills. Experiment 1 showed that the VA span explained a large amount of unique variance in both irregular word and pseudo-word reading accuracy in the French dyslexic participants. Experiment 2 showed that the independent contribution of VA span to reading accuracy remained when age, IQ, vocabulary level, semantic fluency and letter identification skills were controlled. It also showed that the VA span was a strong independent predictor of reading speed. In summary, the VA span as estimated by performance on the letter report tasks accounted for a substantial amount of unique variance in the reading performance of both French- and English-speaking dyslexic children, beyond that explained by phonological skills. Furthermore, in both languages, a majority of dyslexic children exhibited a selective phonological or VA span cognitive deficit, thus providing additional support for the hypothesis that phonological and VA span disorders contribute independently to developmental dyslexia. 
In the remaining sections of this discussion, we will be addressing the following points. First, is the non-phonological deficit that we identified truly visuo-attentional in nature? Could it instead reflect difficulties with single letter processing or iconic memory? Could it even not be specifically visual but rather a reflection of some aspect of phonology that was not tapped by the other phonological tasks that we used? We will finally discuss the potential causal relationship between a VA span disorder and developmental dyslexia.

\section{The visual attentional nature of the deficit}

In this study, VA span was estimated using two letter report tasks inspired from the ones used by Averbach and colleagues to study the processing of letter information perceived during a single fixation (Averbach \& Coriell, 1961; Averbach \& Sperling, 1968).

The whole report task is a simple divided attention task which provides an estimate of the total amount of information that can be extracted in parallel from a brief visual display i.e., the VA span. The task deals with limits on the ability to divide attention between multiple simultaneous targets. The same VA processes are involved at the first stage of processing in partial report. In Experiment 1 and 2, the cue was presented immediately at the offset of the letter string so that performance did not rely on iconic memory. Accordingly, global report only should be affected by a decay of information in iconic memory (Averbach \& Corriell, 1961; Shih \& Sperling, 2002). Contrary to this prediction, the dyslexic participants performed at a similar level on the two tasks and performance strongly correlated suggesting that the VA span disorder did not result from abnormal decay in iconic memory.

According to Bundesen's theory of visual attention (TVA theory: Bundesen, 1990, 1998), letters in multi-letter array compete for access to visual short term memory (parallel competitive processing); the attentional weight reflects how strongly any element competes. 
In the current study, letter arrays were presented for $200 \mathrm{~ms}$, which corresponds to the mean duration of a fixation during reading. In similar conditions, the VA span as indexed by the report tasks was found to predict reading speed during text processing and the number of fixations required for word identification in non dyslexic children (Prado, Dubois, Marendaz, Embs, \& Valdois, submitted). The amount of information processed during this presentation time depends on the processing rate of each element of the array. According to the TVA theory, this processing rate is determined by two factors: the basic sensory effectiveness of each element (which reflects how well an element is processed when presented in isolation) and its relative attentional weight. Global and partial report performance may therefore be seen as reflecting both the ability to identify individual letters quickly and the ability to distribute visual attention across the letter string. The processing rate of single letters was not measured in Experiment 1, so that the relationship we found between the participants' performance in letter report and reading might have reflected one or the other, or both, skills. However, Experiment 2 showed that the dyslexic children did not differ from non dyslexic children in their processing rate of single letters. Furthermore, the regression analyses showed that performance of the dyslexic children on the report tasks accounted for an independent amount of variance in reading even after the effect of single letter processing rate was partialled out. These results suggest that differences in VA span contribute to the poor reading level of dyslexic children, independently of their ability to process single letters.

\section{The Visual attention span is visual}

Even though they involve reporting verbal material, the whole and partial report tasks cannot be considered as primarily phonological or phonological short-term memory tasks for a number of reasons. First, it has been shown that performance in the whole report task is 
barely affected by a concurrent verbal short-term memory task (Scarborough, 1972; Pelli, Burns, Farell, \& Moore, in press). Second, the patterns of errors produced in the whole report task reflect visual rather than verbal confusions (Wolford, 1975). Third, in partial report, a single letter has to be reported, so it is unlikely that phonological short term memory is a major factor as confirmed by Dixon and Shedden (1993) who showed that partial report is only minimally affected by articulatory suppression. Thus, whole and partial report tasks are typically considered as primarily reflecting visual attention and visual short-term memory components (Shih \& Sperling, 2002).

The minimal involvement of phonological processes in the report tasks is further supported by data on developmental dyslexia. In their assessment of two contrasted cases of developmental dyslexia, Valdois et al. (2003) showed that, Laurent, a dyslexic participant with a severe phonological disorder -- weak oral language skills, poor phonological short term memory, poor phoneme awareness -- performed successfully on both the global and partial report tasks. In contrast, Nicolas who performed very poorly on these two tasks exhibited very good phonological processing skills. Although phonological short term memory skills were not assessed here, results from the present study showed that disorders in metaphonological skills and VA span dissociated in most dyslexic participants, so that most dyslexic children with a VA span disorder exhibited no metaphonological problems and vice versa, suggesting that the report tasks and the phonological tasks that we used tap on distinct cognitive processes.

It nevertheless remains that the report tasks do require activation of the phonological information corresponding to letter names. According to Shih and Sperling (2002), letters enter visual short term memory more or less simultaneously and independently -- thus preventing subvocal rehearsal -- so that letter name phonological information (relying on 
serial processing) is secondarily activated on the basis of information in visual short term memory. However, if performance was affected by sluggish activation of letter names or limited visual or phonological short-term memory capacities, global report would be expected to be far more sensitive to such disorders than partial report which requires a single letter to be maintained in STM and named. Here again, the poor performance of the dyslexic participants in partial report, their similar level of performance in global and partial report and the strong correlation between the two VA tasks suggest that performance does not primarily reflect difficulties for activating letter names or maintaining visual or phonological short term memory information. It seems rather that performance on the report tasks mostly reflects contribution of the VA span to encoding of information in visual short term memory. Further research is nevertheless required to confirm this point.

\section{Relationship between VA span deficit and poor reading acquisition}

VA span abilities were found to contribute to exception word reading performance in developmental dyslexia. In accordance with previous reports (Valdois et al., 2003), this finding suggests that a VA span disorder contributes to the poor exception word reading performance (speed and accuracy) of dyslexic children. Such a relationship was found to be independent of the participants' phonological awareness and remained even after controlling for the influence of age, IQ, vocabulary, semantic fluency and letter identification skills. These results have an obvious explanation in the context of the multitrace memory model (Ans et al., 1998). Indeed, within this framework, exception word reading primarily relies on global processing through the activation of word-traces which are created during the reading process each time the entire input orthographic sequence and the entire output phonological 
sequence of the input item are simultaneously available. Therefore, word trace creation requires that all of the letters of the input string be accurately identified across all positions. It follows that a VA span disorder reducing the number of letters which can be identified in parallel should hamper the creation of word traces in long term memory, interfering with the normal development of the global reading procedure and thus preventing normal exception word reading.

However and in line with the self-teaching hypothesis proposed by Share $(1995,1999$; 2004), the ACV model also proposes that reading in analytic mode contributes to the development of specific orthographic knowledge. Indeed, a new word-trace can be created not only following global processing (as previously described) but also, when the whole assembled phonology of the letter-string is kept available in the phonological buffer at the end of analytic processing. It follows that a phonological disorder -- a difficulty in encoding phonological information or maintaining information in the phonological buffer (or both) -affecting analytic processing could have a secondary impact on real word reading by damaging the self-teaching mechanism involved in word-trace acquisition. The model therefore offers a straightforward explanation of the relationship we found between phonological skills and (regular and exception) word reading performance, independently of the dyslexic children's VA span.

However, VA span abilities were also found to be related to pseudo-word reading performance independently of the participants' phoneme awareness skills, thus suggesting that a VA span disorder might disturb pseudo-word reading. The interpretation of this relationship in terms of the ACV98 model is as follows. Analytic processing relies on the creation of memory traces which encode the relationship between orthographic and phonological sub lexical segments. Segment traces are acquired each time children when 
confronted to a written word and its phonological counterpart (e.g., CHAPEAU "hat" is pronounced /Sapo/) are able to simultaneously parse the whole phonological sequence of the spoken word into relevant phonological units (e.g., /S/-/a/-/p/-/o/) together with processing in parallel all of the letters of the corresponding sub lexical orthographic units (e.g., $\mathrm{CH}-\mathrm{A}-\mathrm{P}$ - EAU). A phonological deficit preventing normal phonological parsing should thus affect analytic processing acquisition, a hypothesis well in agreement with current knowledge on the role of phoneme awareness in learning to read. However, the creation of segment traces in memory also requires the VA span to be large enough to process in parallel a sufficient number of letters (e.g., a single letter window would interfere with the processing of digraphs and trigraphs such as "CH" or "EAU”). It follows that a VA span impairment severe enough to drastically reduce the number of focal letters, and prevent normal shifting from one orthographic unit to the other, should impact analytic processing, thus pseudo-word reading.

In sum, the present findings suggest that a VA span disorder -- as well as a phonological disorder -- might impair both real word and pseudo-word reading. However according to the multitrace memory model, a VA span disorder is primarily detrimental to exception word reading and developmental surface dyslexia should arise when the VA span is large enough to process in parallel all of the letters of most graphemes while being not adapted to the length of most word (Valdois et al., 2003). A more severe VA span disorder should result in a pattern of mixed dyslexia, thus predicting that this form of developmental dyslexia might be found independently of any phonological disorder (Valdois et al., in preparation). The present findings therefore provide a potential explanation of the welldocumented prevalence of mixed profiles in developmental dyslexia: mixed profiles might follow from either a single VA span disorder or a single phonological disorder or a double (phonological and VA span) deficit. Further research is required to validate this prediction. 
The multitrace memory model of reading thus postulates a causal relationship between the VA span disorder and difficulties in learning to read. In showing that some dyslexic children exhibit a VA span disorder without any associated phonological problems and that a VA span disorder contributes to the reading outcome of dyslexic children independently of their phonological skills, the present study provides evidence for the VA span disorder as a potentially second core deficit in developmental dyslexia. These very important findings are an essential first step before the issue of causality can be addressed more directly. However, the establishment of some connection from VA span to reading acquisition would require further evidence, in particular from longitudinal and experimental training studies (See Castles \& Coltheart, 2004, for a discussion of the causal hypothesis). Longitudinal studies should be conducted to demonstrate that VA span abilities measured prior to the acquisition of reading ability predict subsequent reading performance. Experimental training studies are required to demonstrate that instruction in VA processing facilitates reading acquisition. Since the seminal paper of Bryant and Impey (1986), it is widely admitted that the establishment of a causal relationship further requires performance of dyslexic participants to be compared to that of normally developing children of the same reading level (Goswami, 2003). According to Bryant and Impey, demonstrating that dyslexic children perform more poorly than younger children of the same reading level provides evidence that their poor performance is not just the consequence of their poor reading level but has to do with the reason why their progress in reading is not normal. Accordingly, the causal hypothesis should be strengthened if demonstrating that the dyslexic children have lower VA span abilities than normal children at the same reading level. Although such a comparison should certainly be helpful, the use of a control group matched for reading age raises a number of important issues. McDougall, 
Borowsky, MacKinnon, and Hymel (2005) convincingly demonstrated that the nature of the tasks used for the matching purpose is not without consequence on the issue of the study. If as expected VA span abilities are primarily related to exception word reading performance and reading speed, matching the dyslexic and control groups on their ability to read real words while taking into account both speed and accuracy should certainly reduce the probability for the dyslexic children with a single VA span disorder to perform at a lower level than reading age matched controls. In contrast, matching the groups on their ability to read pseudo-words might increase the probability to find a significant difference between the control and dyslexic groups' VA span but might decrease the probability to contrast these groups on their phonological skills. Further studies will be needed to identify the criteria that should be used for the purpose of matching for the results to be reliable.

\section{Conclusion}

In summary, the present findings provide evidence that, independently from phonological deficits, a VA span disorder - limiting the number of elements that can be processed in parallel from a brief visual display - also contributes to some dyslexic children's reading difficulties. Future research is needed to establish whether a VA span disorder is causally related to reading acquisition disorders and can be viewed as a second core deficit in developmental dyslexia. Directing attention to a second cognitive disorder independently contributing to developmental dyslexia is a first step towards a better understanding of the heterogeneity of the dyslexic population.

\section{REFERENCES}


Ans, B., Carbonnel, S., \& Valdois, S. (1998). A connectionist multi-trace memory model of polysyllabic word reading. Psychological Review, 105, 678-723.

Arguin, M., \& Bub, D. N. (1993). Single-character processing in a case of pure alexia. Neuropsychologia, 31(5), 435-458.

Averbach, E., \& Coriell, A. S. (1961). Short-term memory in vision. Bell Systems Technical Journal, 40, 309-328.

Averbach, E., \& Sperling, G. (1968). Short term storage of information in vision. In R. N. Haber (Ed.), Contemporary theory and research in visual perception (pp. 196-211). New York: Holt, Rinehart \& Winston.

Bednarek, D.B., Saldana, D., Quintero-Gallego, E., Garcia, I, Grabowska, A. \& Gomez, C.M. (2004). Attentional deficit in dyslexia: a general or specific impairment? NeuroReport, $15,1787-1790$.

Behrmann, M., Moscovitch, M., \& Mozer, M.-C. (1991). Directing attention to words and nonwords in normal subjects and in a computational model: Implications for neglect dyslexia. Cognitive neuropsychology, 8, 213-248.

Breier, J.I., Fletcher, J.M., Foorman, B.R., \& Gray, L.C. (2002). Perception of speech and non speech stimuli by children with and without reading disability and attention deficit hyperactivity disorder. Journal of Experimental Child Psychology, 82, 226-250.

Broom, Y. M., \& Doctor, E. A. (1995). Developmental surface dyslexia: A case study of the efficacy of a remediation programme. Cognitive Neuropsychology, 12, 69-110.

Brunsdon,R. Coltheart, M. \& Nickels, L. (2005). Treatment of irregular word spelling in developmental surface dysgraphia. Cognitive Neuropsychology, 22, 213-251.

Bryant, P. \& Impey, L. (1986). The similarities between normal readers and developmental and acquired dyslexics. Cognition, 24, 121-137. 
Buchholz, J. \& Davies, A.A. (2005). Adults with dyslexia demonstrate space-based and object-based covert attention deficits: shifting attention to the periphery and shifting attention between objects in the left visual field. Brain and Cognition, 57, 30-34.

Bundesen, C. (1990). A theory of visual attention. Psychological review, 97, 523-547.

Bundesen, C. (1998). Visual selective attention: Outlines of a choice model, a race model and a computational theory. Visual Cognition, 5, 287-309.

Caravolas, M., \& Bruck, M. (1993). The Effect of Oral and Written Language Input On Childrens Phonological Awareness - a Cross-Linguistic Study. Journal of Experimental Child Psychology, 55(1), 1-30.

Carroll, J., Davis, P., \& Richman, B. (1971). The American heritage word frequency book. Boston: Houghton Mifflin.

Castles, A., \& Coltheart, M. (1996). Cognitive correlates of developmental surface dyslexia : a single case study. Cognitive Neuropsychology, 13(1), 25-50.

Castles, A., \& Coltheart, M. (2004). Is there a causal link from phonological awareness to success in learning to read? Cognition, 91, 77-111.

Cestnick, L. (2001). Cross-modality temporal processing deficits in developmental phonological dyslexics. Brain and Cognition, 46(3), 319-325.

Cheung, H., Chen, H. C., Lai, C. Y., Wong, O. C., \& Hills, M. (2001). The development of phonological awareness: effects of spoken language experience and orthography. Cognition, 81(3), 227-241.

Coltheart, M., Curtis, B., Atkins, P., \& Haller, M. (1993). Models of reading aloud: Dualroute and parallel-distributed processing approaches. Psychological Review, 100(4), 589-608. 
Coltheart, M., Rastle, K., Perry, C., Langdon, R., \& Ziegler, J. (2001). DRC : A dual route cascaded model of visual word recognition and reading aloud. Psychological Review, $108,204-256$.

Di Betta, A.M. \& Romani, C. (2005). Lexical learning and dysgraphia in a group of adults with developmental dyslexia. Cognitive Neuropsychology, 22, 1-26.

Dixon, P., Gordon, R.-D., Leung, A., \& Di-Lollo, V. (1997). Attentional components of partial report. Journal of Experimental Psychology: Human Perception and Performance, 23, 1253-1271.

Dixon, P., \& Shedden, J. M. (1993). On the nature of the span of apprehension. Psychological Research, 55, 29-39.

Dunn, L.M., Dunn L.M., Whetton, C. \& Burley, J. (1997). The British Picture Vocabulary Scale ( $2^{\text {nd }}$ Edition). Windsor: NFER Nelson.

Duncan, J., Bundesen, C., Olson, A., Humphreys, G., Chavda, S., \& Shibuya, H. (1999). Systematic analysis of deficits in visual attention. Journal of Experimental Psychology: General, 128, 450-478.

Duncan, J., Bundesen, C., Olson, A., Humphreys, G., Ward, R., S., K., van Raamsdonk, M., Rorden, C., \& Chavda, S. (2003). Attentional functions in dorsal and ventral simultanagnosia. Cognitive Neuropsychology, 20, 675-701.

Duncan, L. G., Colé, P., Seymour, P. H. K., \& Magnan, A. (submitted). Differing sequences of metaphonological development in French and English. European Journal of

\section{Cognitive Psychology.}

Durgunoglu, A. Y., \& Oney, B. (1999). A cross-linguistic comparison of phonological awareness and word recognition. Reading and Writing, 11(4), 281-299. 
Facoetti, A. (2004). Reading and selective spatial attention: Evidence from behavioural studies in dyslexic children. In F. Columbus (Ed.), Trends in dyslexia research (pp. 117-150). NY: Nova science publishers.

Facoetti, A., Lorusso, M.L., Cattaneo, C., Galli, R. \& Molteni, M. (2005). Visual and auditory attentional capture are both sluggish in children with developmental dyslexia. Acta Neurobiologiae Experimentalis, 65, 61-72.

Facoetti, A., Lorusso, M. L., Paganoni, P., Cattaneo, C., Galli, R., Umiltà, C., \& Mascetti, G. G. (2003). Auditory and visual automatic attention deficits in developmental dyslexia. Cognitive Brain Research, 16, 185-191.

Facoetti, A., \& Molteni, M. (2001). The gradient of visual attention in developmental dyslexia. Neuropsychologia, 39, 352-357.

Farmer, M. E., \& Klein, R. M. (1995). The evidence for a temporal processing deficit linked to dyslexia: a review. Psychonomic Bulletin \& Review, 2(4), 460-493.

Fawcett, A. J., \& Nicolson, R. I. (1999). Performance of dyslexic children on cerebellar and cognitive tests. Journal of Motor Behavior, 31(1), 68-78.

Fawcett, A. J., \& Nicolson, R. I. (2001). Dyslexia : The role of the cerebellum. In A. J. Fawcett (Ed.), Dyslexia : Theory and Good Practice (pp. 89-105). London: Whurr.

Fawcett, A. J., Nicolson, R. I., \& Dean, P. (1996). Impaired performance of children with dyslexia on a range of cerebellar tasks. Annals of Dyslexia, 46, 259-283.

Frederickson, N., Frith, U. \& Reason, R. (1997). Phonological Assessment Battery. Windsor: NFER Nelson.

Frith, C. (1997). Brain, mind and behaviour in dyslexia. In C. Hulme \& M. Snowling (Eds.), Dyslexia : Biology, cognition and intervention (pp. 1-19). London: Whurr Publishers. 
Frith, U., Wimmer, H. \& Landerl, K. (1998). Differences in phonological recoding in German- and English-speaking children. Scientific Studies of Reading, 2, 31-54.

Giesbrecht, B., \& Dixon, P. (1999). Isolating the interference caused by the cue duration in partial report : a quantitative approach. Memory and Cognition, 27(2), 220-233.

Goswami, U. (2003). Why theories about developmental dyslexia require developmental designs. Trends in Cognitive Sciences, 7, 534-54

Goulandris, N. K., \& Snowling, M. (1991). Visual memory deficits : a plausible cause of developmental dyslexia? Evidence from a single case study. $\underline{\text { Cognitive }}$ Neuropsychology, 8(2), 127-154.

Griffiths, Y. M., \& Snowling, M. (2002). Predictors of exception word and nonword reading in dyslexic children : The severity hypothesis. Journal of Educational Psychology, 94(1), 34-43.

Habekost, T., \& Bundesen, C. (2003). Patient assessment based on a theory of visual attention (TVA): Subtle deficits after a right frontal-subcortical lesion. Neuropsychologia, 41 , 1171-1188.

Hagenaar, R., \& Van Der Heijden, A. H. C. (1995). On the relation between type of arrays and type of errors in partial-report bar-probe studies. Acta Psychologica, 88, 89-104.

Hanley, J. R., \& Gard, F. (1995). A dissociation between developmental surface and phonological dyslexia in two undergraduate students. Neuropsychologia, 33, 909-914. Hanley, R., Hastie, K., \& Kay, J. (1992). Developmental surface dyslexia and dysgraphia : an orthographic processing impairment. Quarterly Journal of Experimental Psychology, 44A(2), 285-319.

Hari, R., \& Renvall, H. (2001). Impaired processing of rapid stimulus sequences in dyslexia. Trends in Cognitive Sciences, 5(12), 525-532. 
Harm, M. W., \& Seidenberg, M. S. (1999). Phonology, reading acquisition, and dyslexia : insights from connectionist models. Psychological Review, 106, 491-528.

Hawelka, S. \& Wimmer, H. (2005). Impaired visual processing of multi-element arrays is associated with increased number of eye movements in dyslexic reading. Vision Research, 45(7), 855-863.

Ho, C. S.H., Chan, W.O., Tsang, S.M. \& Lee, S.H. (2002). The Cognitive Profile and Multiple-Deficit Hypothesis in Chinese Developmental Dyslexia. Developmental Psychology, 38(4), 543-553.

Jacquier-Roux, M., Valdois, S., \& Zorman, M. (2002). ODEDYS: un outil de dépistage des dyslexies. Grenoble: Laboratoire cogni-sciences, IUFM de Grenoble.

Job, R., Sartori, G., Masterson, J., \& Coltheart, M. (1984). Developmental surface dyslexia in Italian. In R. N. Malatesha \& H. A. Whitaker (Eds.), Dyslexia : A global issue (pp. 133-141). The Hague: Martinus Nijhoff.

Juphard, A., Carbonnel, S. \& Valdois, S. (2004). Length effect in reading and in lexical decision: Evidence from skilled reading and a developmental dyslexic participant, Brain \& Cognition, 55, 332-340.

Laberge, D., \& Samuels, S. J. (1974). Toward a theory of automatic information processing in reading. Cognitive psychology, 3, 293-323.

Laberge, D., \& Brown, V. (1989). Theory of attentional operations in shape identification. Psychological review, 96, 101-124.

Landerl, K., Wimmer, H. \& Frith, U. (1997). The impact of orthographic consistency on dyslexia: A German-English comparison. Cognition, 63, 315-334.

Lefavrais, P. (1965). Test de l'Alouette. Paris: Editions du centre de psychologie appliquée. 
Lété, B., Sprenger-Charolles, L. \& Colé, P. (2004). MANULEX : A grade-level lexical database from French elementary-school readers. Behavior Research Methods, Instruments, \& Computers, 36, 156-166.

Livingstone, M. S., Rosen, G. D., Drislane, F. W., \& Galaburda, A. M. (1991). Physiological and anatomical evidence for a magnocellular defect in developmental dyslexia. Proceeds of the National Academy of Science, 88, 7943-7947.

Lovegrove, W. J., Martin, F., \& Slaghuis, W. L. (1986). A theoretical and experimental case for a visual deficit in specific reading disability. Cognitive Neuropsychology, 3, 225267.

McCloskey, M., \& Rapp, B. C. (2000). A visually based developmental reading deficit. Journal of Memory and Language, 43, 157-181.

McDougall, P., Borowsky, R., MacKinnon, G.E. \& Hymel, S. (2005). Process dissociation of sight vocabulary and phonetic decoding in reading: A new perspective on surface and phonological dyslexias. Brain and Language, 92, 185-203.

Merzenich, M. M., Jenkins, W. M., Johnston, P., Schreiner, C., Miller, S., \& Tallal, P. (1996). Temporal processing deficits of language-learning impaired children ameliored by training. Science, $271,77-80$.

Mewhort, D. J. K., Campbell, A. J., Marchetti, F. M., \& Campbell, J. I. D. (1981). Identification, localization, and "iconic memory" : an evaluation of the bar-probe-task. Memory and Cognition, 9(1), 50-67.

Mody, M., Studdert-Kennedy, M., \& Brady, S. (1997). Speech perception deficits in poor readers : auditory processing or phonological coding? Journal of Experimental Child Psychology, 64(2), 199-231. 
Nicolson, R. I., Fawcett, A. J., \& Dean, P. (2001). Dyslexia, development and the cerebellum. Trends Neuroscience, 24(9), 515-516.

Pammer, K., Lavis, R., Hansen, P. \& Cornelissen, P.L. (2004). Symbol-string sensitivity and children's reading. Brain \& Language, 89, 601-610.

Pelli, D.G., Burns, C.W., Farell, B. \& Moore, D.C. (in press). Identifying letters. Vision Research.

Plaut, D. C., McClelland, J. L., Seidenberg, M. S., \& Patterson, K. (1996). Understanding normal and impaired word reading : computational principles in quasi-regular domains. Psychological Review, 103, 56-115.

Prado, C., Dubois, M., Marendaz, C., Embs, J.L. \& Valdois, S. (submitted). Impact of the VA span on children's eye movements during text reading.

Ramus, F., Rosen, S., Dakin, S. C., Day, B. L., Castellote, J. M., White, S., \& Frith, U. (2003). Theories of developmental dyslexia : Insights from a multiple case study of dyslexic adults. Brain, 126(4), 841-865.

Rapp, B. C., \& Caramazza, A. (1991). Spatially determined deficits in letter and word processing. Cognitive Neuropsychology, 8(3/4), 275-311.

Raven, J. C. (1958). Standard progressive matrices: Sets A, B, C, D and E. Cambridge: University Press.

Reichle, E. D., Rayner, K., \& Pollatsek, A. (2003). The E-Z reader model of eye movement control in reading: Comparisons to other models. Behavioral and Brain Sciences, 26, 445-526.

Romani, C., Di Betta, A.M., Tsouknida, E. \& Olson, A. (submitted). Lexical and non lexical processing in developmental dyslexia: A case for different resources and different impairments. 
Romani, C., Olson, A., \& Di Betta, A-M. (2005). Spelling disorders. In M.J. Snowling, M.S. Seidenberg, C. Hulme (Eds), The Science of Reading: A Handbook (pp.431-445). Blackwell.

Romani, C., \& Stringer, M. (1994). Developmental dyslexia : A problem acquiring orthographic/phonological information in the face of good visual memory and good short term memory. Brain and Language, 47, 482-485.

Romani, C., Ward, J., \& Olson, A. (1999). Developmental surface dysgraphia : what is the underlying cognitive impairment? The Quarterly Journal of Experimental Psychology, 52A, 97-128.

Savage, R. \& Frederickson, N. (2005). Evidence of a highly relationship between rapid automatic naming of digits and text-reading speed, Brain and Language, 93, 152-159.

Scarborough, D. L. (1972). Memory for brief visual displays of symbols. $\underline{\text { Cognitive }}$ psychology, 3, 408-429.

Seidenberg, M. S., \& McClelland, J. L. (1989). A distributed, developmental model of word recognition., Psychological Review 96, 523-568.

Serniclaes, W., Sprenger-Charolles, L., Carré, R., \& Démonet, J.-F. (2001). Perceptual discrimination of speech sounds in developmental dyslexia. Journal of Speech, Language and Hearing Research, 44, 384-399.

Seymour, P.H.K., Aro, M. \& Erskine, J.M. (2003). Foundation literacy acquisition in European orthographies. British Journal of Psychology, 94, 143-174.

Share, D. L. (1995). Phonological recoding and self-teaching : Sine qua non of reading acquisition. Cognition, 55, 151-218.

Share, D. L. (1999). Phonological recoding and orthographic learning: a direct test of the selfteaching hypothesis. Journal of Experimental Child Psychology, 72, 95-129. 
Share, D. L. (2004 ). Orthographic learning at a glance: On the time course and developmental onset of self-teaching. Journal of Experimental Child Psychology, 87, 267-298.

Shih, S.-I., \& Sperling, G. (2002). Measuring and modeling the trajectory of visual spatial attention. Psychological Review, 109, 260-305.

Slaghuis, W. L., Lovegrove, W. J., \& Davidson, J. A. (1993). Visual and language processing deficits are concurrent in dyslexia. Cortex, 29, 601-615.

Snowling, M. (2000). Dyslexia. Oxford: Blackwell.

Snowling, M. (2001). From language to reading and dyslexia. Dyslexia, 7(1), 37-46.

Sprenger-Charolles, L., Colé, L., Lacert, P., \& Serniclaes, W. (2000). On subtypes of developmental dyslexia: Evidence from processing time and accuracy scores. Canadian Journal of Experimental Psychology, 54, 87-103.

Stein, J. F. (1991). Vision and visual dyslexia. Boca Raton, Florida: CRC Press.

Stein, J. F. (2001). The magnocellular theory of developmental dyslexia. Dyslexia, 7(1), 1236.

Stein, J. F. (2003). Visual motion sensitivity and reading. Neuropsychologia, 41, 1785-1793.

Stein, J. F., \& Fowler, M. S. (1993). Unstable binocular control in children with specific reading retardation. Journal of Research in Reading, 16, 30-45.

Stein, J. F., Talcott, J., \& Witton, C. (2001). The sensorimotor basis of developmental dyslexia. In A. J. Fawcett (Ed.), Dyslexia : Theory and Good Practice (pp. 65-88). London: Whurr.

Stein, J. F., \& Walsh, V. (1997). To see but not to read ; The magnocellular theory of dyslexia. Trends Neuroscience, 20(4), 147-152. 
Tallal, P. (1980). Auditory temporal perception, phonics, and reading disabilities in children. Brain and Language, 9(2), 182-198.

Tallal, P., Miller, S., Bedi, G., Byma, G., Wang, X., Nagarajan, S., Schreiner, C., Jenkins, W. M., \& Merzenich, M. M. (1996). Language comprehension in language-learning impaired children improved with acoustically modified speech. Science, 271(81-84).

Tallal, P., Miller, S., \& Fitch, R. H. (1993). Neurological basis of speech : A case for the prominence of temporal processing? In P. Tallal, A. Galaburda, R. Llinas \& C. V. Heuler (Eds.), Annals of the New York Academy of Sciences (Vol. 682, pp. 27-37). New York: New York Academy of Sciences.

Tallal, P., Miller, S.L., Jenkins, W.M. \& Merzenich, M.M. (1997). The role of temporal processing in developmental language-based learning disorders: Research and clinical implications. In B.A. Blachman (Ed.). Foundations of reading acquisition and dyslexia: Implications for early intervention (pp. 49-66). Mahwah: NJ: Erlbaum.

Temple, C. M. (1984). Surface dyslexia in a child with epilepsy. Neuropsychologia, 22, 569576.

Valdois, S., Bosse, M.-L., Ans, B., Carbonnel, S., Zorman, M., David, D., \& Pellat, J. (2003). Phonological and visual processing deficits can dissociate in developmental dyslexia : Evidence from two case studies. Reading and Writing: An Interdisciplinary Journal, $16,541-572$.

Valdois, S., Bidet-Ildei, C., Prado, C., lassus, D., \& Orliaguet, J-P. (in preparation). New insights on mixed dyslexia: evidence from a single case study.

Valdois, S., Juphard, A., Baciu, M., Ans, B., Peyrin, C., Segebarth, C. \& Carbonnel, S. (in press). Polysyllabic pseudo-word processing in reading and lexical decision: 
convergent evidence from behavioural data, connectionist simulations and functional MRI. Brain Research.

Vellutino, F. R., Fletcher, J. M., Snowling, M. J., \& Scanlon, D. M. (2004). Specific reading disability (dyslexia): what have we learned in the past four decades? Journal of child psychology and psychiatry, 45, 2-40.

Vidyasagar, T. R. (2004). Neural underpinnings of dyslexia as a disorder of visuo-spatial attention. Clinical and Experimental Optometry, 87, 4-10.

Wilkinson, G.S. (1993). Wide Range Achievement Test 3. London: The Psychological Corporation.

Wimmer, H. (1993). Characteristics of the developmental dyslexia in a regular writing system. Applied Psycholinguistics, 14, 1-33.

Wimmer, H., Mayringer, H., \& Landerl, K. (2000). The double-deficit hypothesis and difficulties in learning to read a regular orthography. Journal of Educational Psychology, 92, 668-680.

Wolf, M., \& Bowers, P. G. (1999). The double-deficit hypothesis for the developmental dyslexias. Journal of Educational Psychology, 91(3), 415-438.

Wolf, M., Goldberg O'Rourke, A., Gidney, C., Lovett, M., Cirino, P., \& Morris, R. (2002). The second deficit : An investigation of the independence of phonological and naming-speed deficits in developmental dyslexia. Reading and writing: an interdisciplinary journal, 15, 43-72.

Wolford, G. (1975). Perturbation model for letter identification. Psychological review, 82, 184-199. 
Ziegler, J. C., \& Goswami, U. (2005). Reading acquisition, developmental dyslexia, and skilled reading across languages: a psycholinguistic grain size theory. Psychological Bulletin, 131(1), 3-29. 


\section{Appendix 1}

\section{Experiment 1: French Word and Pseuso-Word Reading Lists}

\section{Consistent Words $(\mathrm{n}=40)$}

Low frequency. Sac, congé, dorade, rigueur, asile, approche, piège, bottine, hausse, astronome, alchimie, avanie, courroie, baril, cargo, esquif, cric, cagoule, acrobate, bise.

High frequency. Faute, nuit, vague, montagne, soin, soif, mal, sauvage, mission, fuite, élan, animé, talon, splendeur, maman, pardon, caravelle, électron, jaloux, envoyé.

\section{Exception Words $(\mathrm{n}=40)$}

Low frequency. Net, galop, dolmen, respect, bourg, aiguille, poêle, baptême, oignon, aquarelle, orchidée, agenda, compteur, stand, toast, escroc, cake, chorale, aquarium, paon High frequency. Femme, hier, ville, monsieur, sept, août, dix, seconde, million, fusil, écho, tronc, tabac, orchestre, moyen, parfum, cacahuète, équateur, gentil, examen $\underline{\text { Pseudo-Words }}$

Jani, comari, drouve, dute, stotée, vali, rasque, bainlien, prin, stur, boinde, toinpare, asdion, scrupt, falm, mona, notavuté, tist, tein, dafineur, luma, voin, froctare, trinspart, monicare, brinte, munate, expardose, pourte, dirc, miscla, reimbure, plaction, dour, faltrège, molide, dapoir, explague, nileur, voidrine, bascorni, mati, slop, tamute, crou, doupelle, stip, proncite, tsor, tourpeur, corabone, nomiré, tolain, popi, cobane, cain, antimadé, chanvion, ascodeau, scolp, tide, volate, codeau, maldre, dodicace, trictour, ascole, malocage, dare, ipta, torc, pélace, aripte, coravine, tame, bion, crapte, reau, fadole, scropale, pnou, teur, reinte, spactègle, coripuce, tolape, doir, modilane, exirte, comoride.

\section{Experiment 2: English Word and Pseuso-Word Reading Lists}

\section{$\underline{\text { Consistent Words }}$}


Smog, nothing, marathon, trunk, help, wish, rainbow, seven, report, bake, party, telling, window, calling, shock, radish, thorn, athletic, shudder, frog

\section{Exception Words}

Wolf, yacht, rhythm, sword, sugar, island, surface, regime, furious, ghost, give, meringue, cough, ocean, silence, whisper, foreign, iron, bouquet, echo

\section{$\underline{\text { Pseudo-Words }}$}

Drock, bantost, thiffer, losh, shathom, retash, krog, gommy, lumnooth, fleg, golthom, lishoo, torlep, geronth, cheed, avisher, meesh, imchim, nart, plish 
Table 1

Mean Scores (SD) and Ranges of Reading, Phonological and Visual Attentional tasks for the

Dyslexic and Chronological Age Control Participants

\begin{tabular}{|c|c|c|c|c|}
\hline Tasks & Max & Dyslexics & CA controls & $\begin{array}{c}\mathrm{t} \text { test } \\
(\mathrm{dl}=121)\end{array}$ \\
\hline \multicolumn{5}{|l|}{ Reading } \\
\hline Regular Word (RW) & 40 & $33.5(5.4) ; 17-40$ & $39.2(1.1) ; 35-40$ & $7.67 * * *$ \\
\hline Exception Word (EW) & 40 & $25.6(8.8) ; 8-40$ & $36.5(2.4) ; 30-40$ & $8.90 * * *$ \\
\hline Pseudo-Word (PW) & 40 & $28.0(7.3) ; 10-40$ & 34.3 (2.9); 27-40 & $6.03 * * *$ \\
\hline \multicolumn{5}{|l|}{ Phoneme Awareness } \\
\hline Segmentation (SEG) & 20 & $14.9(4.6) ; 1-20$ & $15.8(2.4) ; 11-20$ & 1.23 \\
\hline Deletion (DEL) & 20 & $15.6(3.8) ; 6-20$ & $17.8(2.4) ; 10-20$ & $3.75 * * *$ \\
\hline Acronym (ACR) & 15 & $10.5(3.6) ; 0-15$ & $12.3(2.2) ; 4-15$ & $3.14 * *$ \\
\hline \multicolumn{5}{|l|}{ Visual Attention } \\
\hline Whole report string (STR) & 20 & $5.15(5.5) ; 0-18$ & $11.9(4.7) ; 0-19$ & $7.24 * * *$ \\
\hline Whole report letters (LET) & 100 & 73.10 (15.2); 34-99 & 88.8 (7.6); 60-99 & $7.02 * * *$ \\
\hline Partial report (PAR) & 50 & $38.32(7.2) ; 13-50$ & $43.5(3.9) ; 32-50$ & $4.81 * * *$ \\
\hline
\end{tabular}




\section{Table 2}

Correlations among Age, Reading, Phoneme awareness (P.A.) and VA span tasks for all Participants $(\mathrm{N}=123)$

\begin{tabular}{|c|c|c|c|c|c|c|c|c|c|}
\hline & RW & EW & PW & SEG & DEL & ACR & STR & LET & PAR \\
\hline Age & $.29 * *$ & $.39 * * *$ & $.20 *$ & -.17 & .04 & $.20 *$ & $.34 * * *$ & $.31 * * *$ & $.20 *$ \\
\hline \multicolumn{10}{|l|}{ Reading } \\
\hline RW & & $.83 * * *$ & $.78 * * *$ & $.20 *$ & $.28 * *$ & $.33 * * *$ & $.56 * * *$ & $.61 * * *$ & $.49 * * *$ \\
\hline EW & & & $.70 * * *$ & $.22 *$ & $.32 * * *$ & $.36 * * *$ & $.67 * * *$ & $.69 * * *$ & $.52 * * *$ \\
\hline PW & & & & $.34 * * *$ & $.46 * * *$ & $.32 * * *$ & $.61 * * *$ & $.65 * * *$ & $.52 * * *$ \\
\hline \multicolumn{10}{|l|}{ P.A. } \\
\hline SEG & & & & & $.49 * * *$ & $.40 * * *$ & .09 & .12 & .10 \\
\hline DEL & & & & & & $.47 * * *$ & $.27 * *$ & $.21 *$ & $.20 *$ \\
\hline ACR & & & & & & & $.31 * * *$ & $.24 * *$ & $.18^{*}$ \\
\hline \multicolumn{10}{|l|}{ VA Span } \\
\hline STR & & & & & & & & $.90 * * *$ & $.64 * * *$ \\
\hline LET & & & & & & & & & $.69 * * *$ \\
\hline
\end{tabular}




\section{Table 3}

Partial Correlations (controlling for Chronological Age) among Reading, (PA) and VA span tasks for the French Dyslexic Children.

\begin{tabular}{|c|c|c|c|c|c|c|c|c|}
\hline & EW & PW & SEG & DEL & ACR & STR & LET & PAR \\
\hline \multicolumn{9}{|c|}{ Reading } \\
\hline RW & $.73 * * *$ & $.74 * * *$ & $.33 * *$ & .20 & .23 & $.37 * *$ & $.40 * * *$ & $.33 * *$ \\
\hline EW & ---- & $.60 * * *$ & $.38 * *$ & .21 & .21 & $.48 * * *$ & $.50 * * *$ & $.34 * *$ \\
\hline PW & & ---- & $.49 * * *$ & $.42 * * *$ & $.25^{*}$ & $.51 * * *$ & $.54 * * *$ & $.44 * * *$ \\
\hline \multicolumn{9}{|l|}{$P A$} \\
\hline SEG & & & ---- & $.53 * * *$ & $.44 * * *$ & .20 & .20 & .15 \\
\hline DEL & & & & ---- & $.43 * * *$ & .17 & .07 & .09 \\
\hline ACR & & & & & ---- & .12 & .03 & .02 \\
\hline \multicolumn{9}{|c|}{$V A$ span } \\
\hline STR & & & & & & ---- & $.85^{* * *}$ & $.53 * * *$ \\
\hline LET & & & & & & & ---- & $.60 * * *$ \\
\hline
\end{tabular}


Table 4

Principal Components Analysis Showing Rotated Factor Loadings on the Phonological Tasks, the Visual Attentional Tasks and Age

Factor Loadings

Factor 1: $\quad$ Factor 2: $\quad$ Factor 3:

$\begin{array}{lll}\text { Tasks } & \text { Vhonological Chronological age }\end{array}$

\begin{tabular}{llll}
\hline AGE & .20 & -.02 & $\mathbf{9 2}$ \\
SEG & .07 & $\mathbf{. 9}$ & -.32 \\
DEL & .17 & $\mathbf{. 1}$ & .01 \\
ACR & .12 & .76 & .36 \\
STR & $\mathbf{. 9}$ & .15 & .22 \\
LET & $\mathbf{. 9 4}$ & .10 & .14 \\
PAR & $\mathbf{8 6}$ & .06 & -.01 \\
\hline
\end{tabular}




\section{Table 5}

Results of Hierarchical Regressions Conducted for the Dyslexic Children: Contribution of each Factor Scores (Age, Phonological and Visual) to Reading Age (RA), Regular Word (RW), Exception Word (EW) and Pseudo-Word (PW) Reading. Age Variable was Systematically Entered at the First Step.

\begin{tabular}{|c|c|c|c|c|}
\hline & RA & RW & EW & PW \\
\hline Factor & $\mathrm{R}^{2}$ change & $\mathrm{R}^{2}$ change & $\mathrm{R}^{2}$ change & $\mathrm{R}^{2}$ change \\
\hline 1.Age & $.230 * * *$ & $.071 *$ & $.132 * *$ & .011 \\
\hline 2.Phonological & .000 & .048 & .041 & $.139 * *$ \\
\hline 3. Visual & $.196 * * *$ & $.221 * * *$ & $.294 * * *$ & $.364 * * *$ \\
\hline 2.visual & $.193^{* * *} *$ & $.190 * * *$ & $.260 * * *$ & $.301 * * *$ \\
\hline 3.phonological & .004 & $.078 * *$ & $.075 * *$ & $.203 * * *$ \\
\hline TOTAL & $.426^{* * *}$ & $.340 * * *$ & $.467 * * *$ & $.514 * * *$ \\
\hline
\end{tabular}


Table 6

Experiment 2: Characteristics of the Dyslexic and Chronological Age Control Participants.

\begin{tabular}{llllll}
\hline & \multicolumn{2}{c}{ 29 Dyslexics } & & 23 Controls & T test \\
& Mean (SD) & Range & Mean (SD) & Range & \\
\cline { 2 - 5 } Age & $125.2(8.4)$ & $109-143$ & $125.7(7.7)$ & $114-139$ & $\mathrm{t}=-0.21, \mathrm{p}=.830$ \\
Non verbal IQ & & & & & \\
Standard score: & $108.1(12.3)$ & $90-125$ & $114.1(9.0)$ & $90-125$ & $\mathrm{t}=-1.97, \mathrm{p}=.054$ \\
\hline Reading WRAT & & & & & \\
Standard score & $81.4(6.9)$ & $64-93$ & $112.9(13.9)$ & $96-146$ & $\mathrm{t}=-10.7$ \\
Percentile: & $12.9(8.5)$ & $1-32$ & $72.7(22.1)$ & $39-99$ & $\mathrm{t}=-13.4, \mathrm{p}<.0001$ \\
Spelling WRAT & & & & & \\
Standard score & $82.2(5.9)$ & $72-98$ & $109.5(9.5)$ & $92-123$ & $\mathrm{t}=-12.6$ \\
Percentile: & $13.3(10.2)$ & $3-45$ & $70.8(20.5)$ & $30-94$ & $\mathrm{t}=-13.2, \mathrm{p}<.0001$ \\
\hline
\end{tabular}


Table 7

Experiment 2: Scores of the dyslexic and control groups in the word reading (raw scores), phonological (standard scores), visual attentional (raw scores) and control (standard scores for vocabulary and semantic fluency; raw scores for letter identification) tasks.

\begin{tabular}{|c|c|c|c|c|c|}
\hline & $\begin{array}{l}29 \text { Dyslexics } \\
\text { Mean (SD) }\end{array}$ & Range & $\begin{array}{l}23 \text { Controls } \\
\text { Mean (SD) }\end{array}$ & Range & t-test \\
\hline \multicolumn{6}{|l|}{$\begin{array}{l}\text { Reading tasks } \\
\text { Regular words }\end{array}$} \\
\hline Score & $15.1(4.6)$ & $4-20$ & $19.7(0.7)$ & $17-20$ & $4.65 * * *$ \\
\hline Speed & $2.4(1.7)$ & $0.7-7.8$ & $0.9(0.4)$ & $0.5-2.2$ & $4.12 * * *$ \\
\hline \multicolumn{6}{|l|}{ Irregular words } \\
\hline Score & $9.5(4.4)$ & $1-17$ & $16.9(1.9)$ & $12-19$ & $7.47 * * *$ \\
\hline Speed & $5.1(5.0)$ & $1.3-23.5$ & $1.3(0.6)$ & $0.6-3.5$ & $3.63 * * *$ \\
\hline \multicolumn{6}{|l|}{ Pseudo words } \\
\hline Score & $8.9(5.6)$ & $0-20$ & $15.7(5.6)$ & $6-20$ & $4.96 * * *$ \\
\hline Speed & $4.6(3.9)$ & $1.5-20.3$ & $1.6(0.6)$ & $0.7-3.3$ & $3.66 * * *$ \\
\hline \multicolumn{6}{|c|}{ Phonological tasks } \\
\hline Spoonerism & $16.6(5.4)$ & $7-28$ & $24.3(4.6)$ & $15-30$ & $5.47 * * *$ \\
\hline Alliteration & $13.2(4.4)$ & $5-25$ & $14.8(3.7)$ & $11-25$ & 1.37 \\
\hline Rhyme fluency & $8.6(3.2)$ & $4-14$ & $11.0(3.4)$ & $6-17$ & $2.62 *$ \\
\hline \multicolumn{6}{|c|}{ Visual attentional tasks } \\
\hline GloREP Letters & $72.9(12.0)$ & $50-91$ & $87.0(7.3)$ & $70-99$ & $4.95 * * *$ \\
\hline GloREP Strings & $4.3(4.4)$ & $0-14$ & $9.9(4.7)$ & $1-19$ & $4.44 * * *$ \\
\hline Partial report & $41.6(7.1)$ & $23-48$ & $45.1(3.7)$ & $37-49$ & $2.15^{*}$ \\
\hline \multicolumn{6}{|l|}{ Control tasks } \\
\hline Semantic fluency & $23.4(5.7)$ & $9-31$ & $25.8(6.5)$ & $12-36$ & 1.37 \\
\hline $\begin{array}{l}\text { Vocabulary } \\
\text { (BPVS) }\end{array}$ & $98.3(14.0)$ & $71-137$ & $105.5(11.4)$ & $80-133$ & $1.99 *$ \\
\hline $\begin{array}{l}\text { Letter } \\
\text { identification }\end{array}$ & $103.8(28.3)$ & $34-136$ & $114.5(25.1)$ & $58-148$ & 1.40 \\
\hline
\end{tabular}

$* \mathrm{p}<.05 ; * * \mathrm{p}<.01 ; * * * \mathrm{p}<.001$ 
Table 8

Experiment 2: Correlations among the tasks for the whole British population $(\mathrm{N}=52)$

\begin{tabular}{|c|c|c|c|c|c|c|c|c|c|c|c|c|c|c|c|c|}
\hline & IQ & $\mathrm{RW}$ & $\begin{array}{l}\text { RW } \\
\text { speed }\end{array}$ & EW & $\begin{array}{l}\text { EW } \\
\text { speed }\end{array}$ & PW & $\begin{array}{l}\text { PW } \\
\text { speed }\end{array}$ & SPO & ALL & RHY & STR & LET & PAR & VOC & SEM & IDE \\
\hline Age & .01 & $.36 * *$ & -.26 & $.28^{*}$ & -.10 & .20 & -.12 & .09 & .06 & .09 & .14 & .18 & .24 & .16 & .22 & .13 \\
\hline IQ & & $.30 *$ & $-.40 * *$ & $.43 * *$ & -.21 & .07 & $-.27 *$ & .21 & -.04 & .16 & $.38 * *$ & $.38 * *$ & $.42 * *$ & $.39 * *$ & .18 & .25 \\
\hline \multicolumn{17}{|c|}{ Reading } \\
\hline RW & & & $-.58 * * *$ & $.83 * * *$ & $-.61 * * *$ & $.66^{* * *}$ & $-.60 * * *$ & $.46^{* * *}$ & $.36 * *$ & $.27 *$ & $.58 * * *$ & $.68 * * *$ & $.41 * *$ & $.31 *$ & .12 & .26 \\
\hline speed & & & & $-.70 * * *$ & $.68 * * *$ & -.25 & $.78 * * *$ & $-.28^{*}$ & -.05 & .02 & $-.56 * * *$ & $-.69 * * *$ & $-.32 *$ & -.19 & -.13 & $-.39 * *$ \\
\hline EW & & & & . & $-.59 * * *$ & $.62 * * *$ & $-.62 * * *$ & $.51 * * *$ & $.34^{*}$ & $.28^{*}$ & $.64 * * *$ & $.71 * * *$ & $.40 * *$ & $.39 * *$ & .16 & $.41 * *$ \\
\hline speed & & & & & & $-.35^{*}$ & $.89 * * *$ & $-.35^{*}$ & $-.36 * *$ & $-.30 *$ & $-.48 * * *$ & $-.64 * * *$ & -.22 & -.17 & -.16 & -.15 \\
\hline PW & & & & & & & $-.38 * *$ & $.61 * * *$ & $.46 * * *$ & $.34^{*}$ & $.36 * *$ & $.40 * *$ & .24 & $.29 *$ & .20 & .10 \\
\hline speed & & & & & & & & $-.38 * *$ & $-.34 *$ & -.16 & $-.51 * * *$ & $-.69 * * *$ & -.26 & -.20 & -.17 & $-.28 *$ \\
\hline \multicolumn{17}{|c|}{ Phoneme Awareness } \\
\hline SPO & & & & & & & & & $.52 * * *$ & $.58 * * *$ & $.45^{* *}$ & $.42 * *$ & .25 & $.35^{*}$ & $.43 * *$ & .23 \\
\hline ALL & & & & & & & & & & $.48 * * *$ & .08 & .12 & -.11 & .21 & $.31 *$ & .11 \\
\hline RHY & & & & & & & & & & & .24 & .21 & .01 & $.28^{*}$ & $.47 * * *$ & .13 \\
\hline \multicolumn{17}{|c|}{ Visual Attention } \\
\hline STR & & & & & & & & & & & & $.92 * * *$ & $.47 * * *$ & .07 & $.30 *$ & $.36^{*}$ \\
\hline LET & & & & & & & & & & & & & $.49 * * *$ & .09 & .22 & $.41^{* *}$ \\
\hline PAR & & & & & & & & & & & & & & .22 & .18 & .25 \\
\hline
\end{tabular}




\section{Control tasks}

Vocabulary (VOC)

Semantic fluency (SEM)

Letter identification (IDE)

$* \mathrm{p}<.05 ; * * \mathrm{p}<.01 ; * * * \mathrm{p}<.001$ 
Table 9

Experiment 2: Principal Components Analysis Showing Rotated Factor Loadings on the Phonological and Visual Attentional Tasks

\begin{tabular}{|c|c|c|}
\hline \multirow[b]{3}{*}{ Tasks } & \multicolumn{2}{|c|}{ Factor Loadings } \\
\hline & Factor 1: & Factor 2: \\
\hline & Visual & Phonological \\
\hline SPO & .42 & .76 \\
\hline ALL & -.06 & .84 \\
\hline RHY & .12 & .82 \\
\hline STR & .92 & .17 \\
\hline LET & .92 & .17 \\
\hline PAR & .75 & -.15 \\
\hline
\end{tabular}


Table 10

Experiment 2: Results of Hierarchical Regressions Conducted for the Dyslexic Children: Contribution of each Factor Scores (Phonological and Visual) to Regular Word (RW), Exception Word (EW) and Pseudo-Word (PW) Reading accuracy and speed. The First Step corresponds to the forced entry of five control variables (age, IQ, vocabulary, semantic fluency and letter identification threshold).

\begin{tabular}{|c|c|c|c|c|c|c|}
\hline \multirow[b]{3}{*}{ Step } & \multicolumn{2}{|c|}{ RW } & \multicolumn{2}{|c|}{ EW } & \multicolumn{2}{|c|}{ PW } \\
\hline & score & speed & score & speed & score & speed \\
\hline & $\mathrm{R}^{2}$ change & $\mathrm{R}^{2}$ change & $\mathrm{R}^{2}$ change & $\mathrm{R}^{2}$ change & $\mathrm{R}^{2}$ change & $\mathrm{R}^{2}$ change \\
\hline 1.Controls & $.429 *$ & $.436^{*}$ & $.490 *$ & .031 & .351 & .100 \\
\hline 2.Phonological & .107 & .002 & $.123 *$ & .095 & .110 & .098 \\
\hline 3. Visual & $.247 * * *$ & $.135 *$ & $.080 *$ & $.260 *$ & .065 & $.208 *$ \\
\hline 2.visual & $.168 *$ & $.135^{*}$ & .038 & .181 & .030 & .138 \\
\hline 3.phonological & $.186 * * *$ & .002 & $.165^{* *}$ & $.174 *$ & $.146^{*}$ & $.167 *$ \\
\hline TOTAL & $.783 * * *$ & $.573 *$ & $.693 * *$ & .385 & $.523 *$ & .405 \\
\hline
\end{tabular}


Figure Captions

Figure 1. Architecture of the multitrace connectionist model of reading (Ans, Carbonnel \& Valdois, 1998); $O 1=$ input orthographic layer, $O 2=$ orthographic echo layer, $E M=$ episodic memory, $P=$ output phonological layer, $V A W=$ visual attentional window. The phonological and orthographic layers are sets of unconnected clusters of elementary units coding for phonemes and alphabetic characters respectively. The arrows depict fully distributed modifiable connections. The double arrow symbolises a matching check procedure comparing the identity of the orthographic echo generated over $O 2$ with the $O 1$ input pattern. Units within the VAW are maximally and equally activated.

Figure 2. Experiment 1: Repartition of the French dyslexic (black dots) and control (white squares) participants according to their visual and phonological factorial coefficients.

Figure 3. Experiment 2: Repartition of the British dyslexic (black dots) and control (white squares) participants according to their visual and phonological factorial coefficients. 
Figure 1

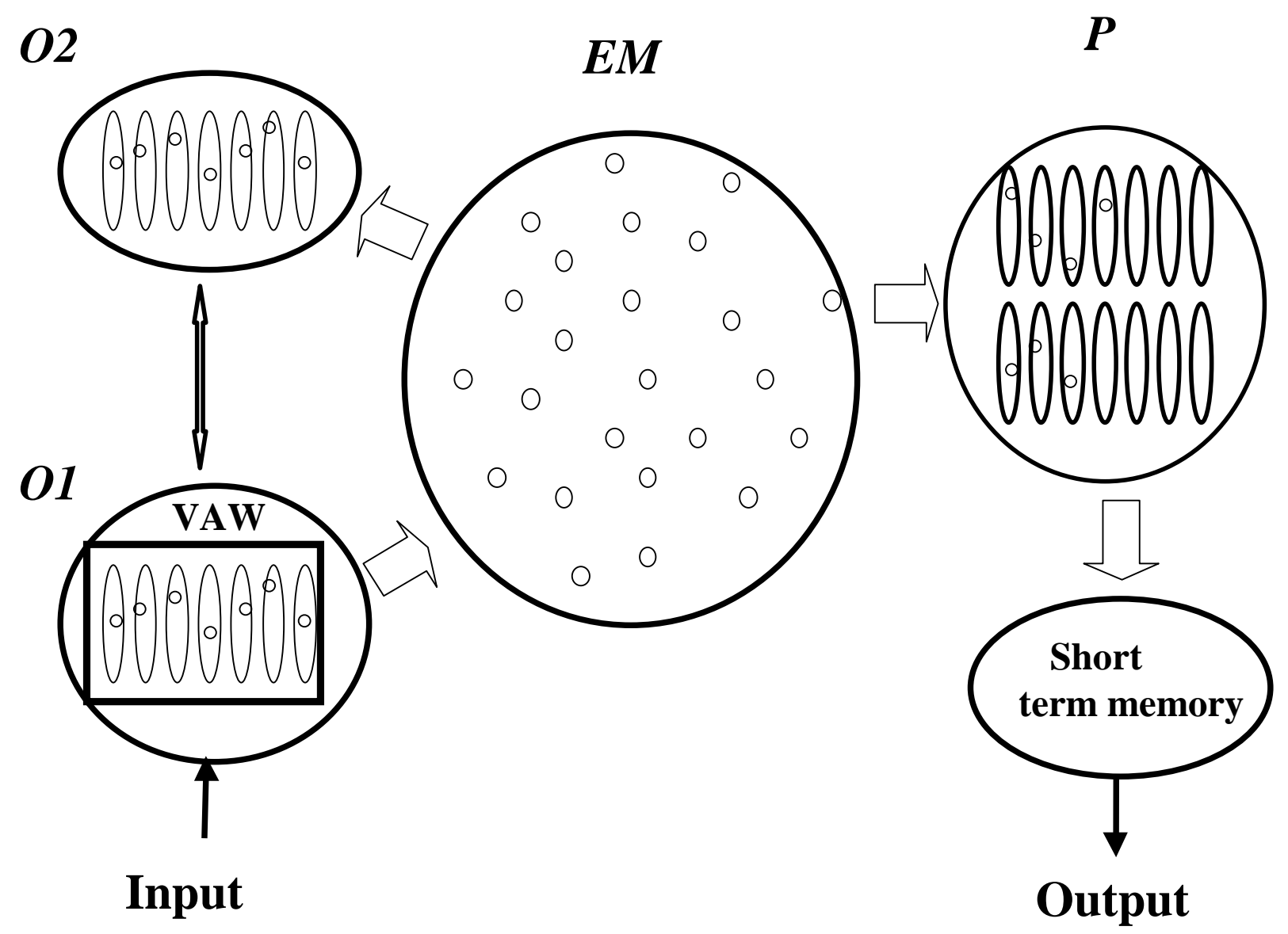


Figure 2:

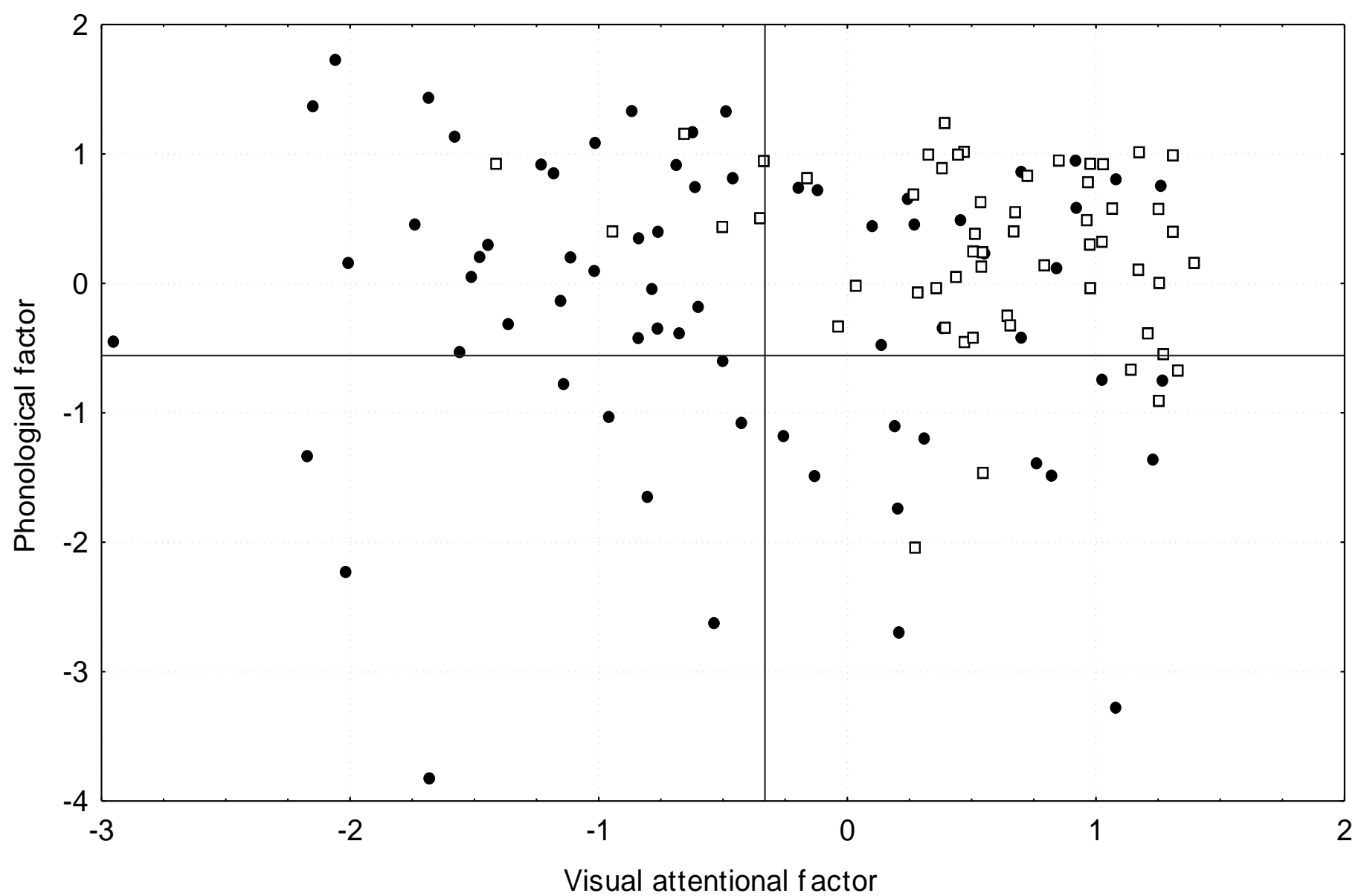


Figure 3

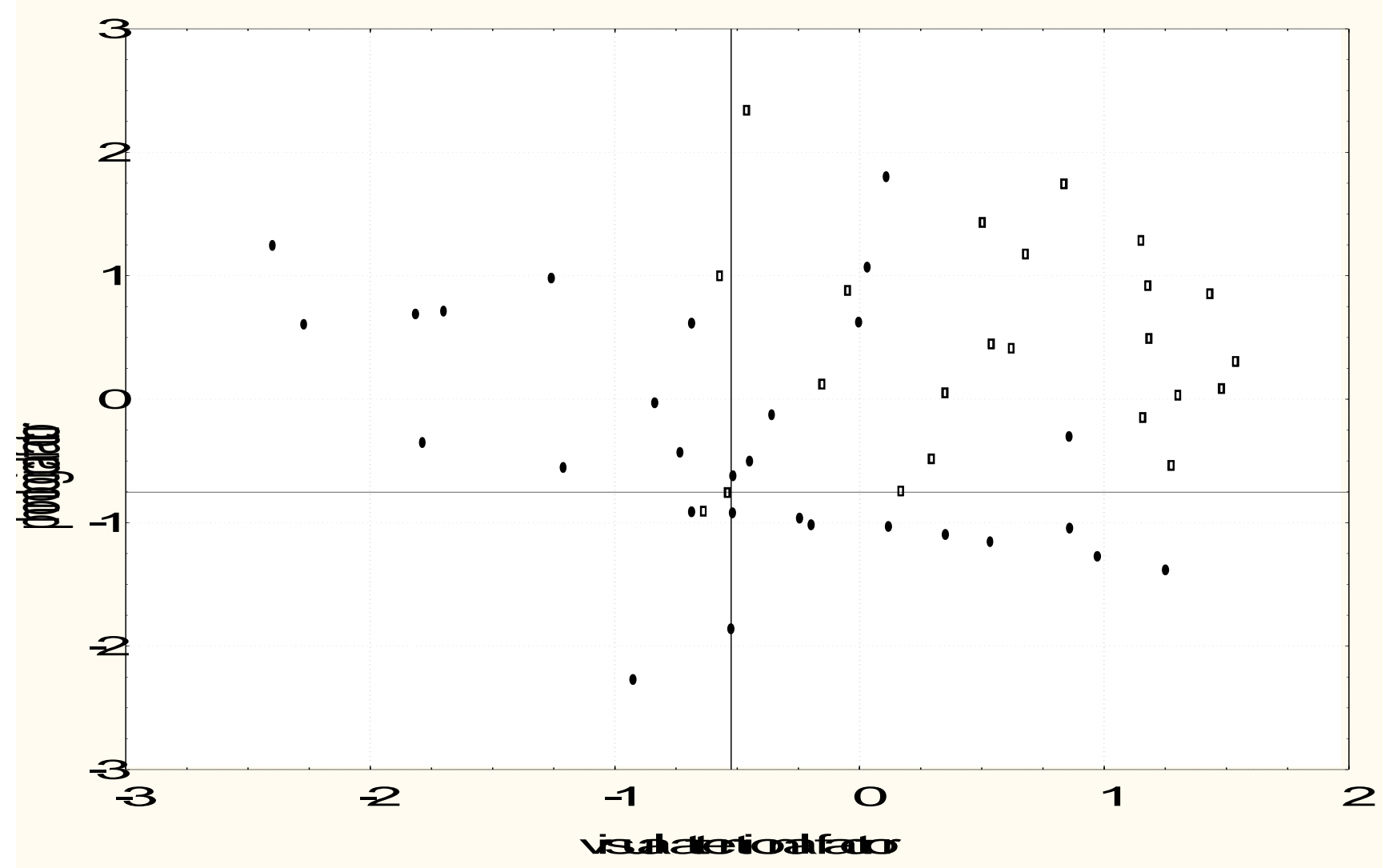

